\title{
BARCINO AUGUSTEA Y JULIO-CLAUDIA. DINÁMICA SOCIO-ECONÓMICA DE LA PRODUCCIÓN Y EL COMERCIO DEL VINO LAYETANO
}

\section{AUGUSTAN AND JULIO-CLAUDIAN BARCINO. SOCIO-ECONOMIC DYNAMICS OF THE PRODUCTION AND COMMERCE OF LAETANIAN WINE}

\author{
JORDI MIRÓ CANALS \\ Institut Català d'Arqueologia Clàssica (ICAC). Tarragona \\ Investigador adscrito \\ Correo-e: jmiro@icac.cat D https://orcid.org/0000-0002-9120-6623 \\ ResearcherID: https://publons.com/researcher/3858770
}

\begin{abstract}
Resumen: Este trabajo pretende ser una síntesis de la función de la colonia de Barcino en la producción y el comercio del vino layetano en época augustea y julio-claudia. Se contemplan las tres etapas del proceso, esto es, la producción, articulada alrededor de las alfarerías de ánforas y de las villae productoras y el almacenaje; los puertos de embarque de estas producciones, el comercio marítimo a través de los pecios; y finalmente, los consumidores. Los tipos anfóricos son la Pascual 1 y la Dressel 3-2. Asimismo, la epigrafía de estas ánforas y la toponimia local nos aportan la principal información para conocer a los protagonistas de estas actividades socioeconómicas: libres, libertos y esclavos y su papel en las mismas. Se insiste especialmente en las gentes bien conocidas en Barcino por la epigrafía honorífica y monumental (Licinii, Cornelii, etc.).
\end{abstract}

Palabras claves: Pascual 1; Dressel 3-2; Layetania; figlinae; epigrafía anfórica; ánforas romanas

\section{INTRODUCCIÓN}

Desde los años sesenta, con la labor pionera de Ricard Pascual (1962 y 1977) en la identificación del tipo de ánfora que llevará su apellido, y años después con la de André Tchernia (1971), centrado en las Dressel 2-4
Abstract: This work aims to be a synthesis of the role of the Barcino colony in the production and trade of Layetan wine in the Augustan and Julio-Claudian period. The three stages of the process are investigated: the production, shaped around amphora kilns and the producing villae and storage; the shipping ports of these productions, the maritime trade and shipwrecks; and finally the consumers. The Amphoric typologies are Pascual 1 and Dressel 3-2. Likewise, epigraphy of these amphorae and local toponymy provide us the main information to know the protagonists of these socio-economic activities (aristocracy, freedmen and slaves) and their role. Special emphasis is placed on the well-known gentes in Barcino in honorific and monumental epigraphy (Licinii, Cornelii, etc.).

Keywords: Pascual 1; Dressel 3-2; Layetania; figlinae; amphora epigraphy; Roman amphorae

tarraconenses, se abrió el camino para el estudio de la producción y exportación del vino de la Tarraconense envasado en ánfora. De hecho, era la constatación arqueológica del éxito de un producto provincial, según entendemos por las citas de Plinio (Nat. 14.71) y Marcial (Mart. 1.26, 7.53, 13.118) relativas al consumo 
de vino layetano en Roma. Desde entonces, en los estudios de conjunto y en particular sobre la Barcelona romana se fue incorporando y valorando el papel de la colonia en esta actividad económica (p.ej.: Tarradell 1975: 127-129 y 1978: 230-231, Rodà 1991).

Acerca de los motivos de Augusto para fundar la colonia ex novo entre el 15-9 a.C. (p. ej.: Granados 1991: 162-163, IRC IV 52-53), veremos en estas páginas cómo la ciudad y su territorio se vieron envueltos en un proceso de cambio radical en lo que concierne a las estructuras económicas y sociales, ya que su fundación debió obedecer a una decisión económica, la de estimular y controlar la producción del vino layetano, un producto de gran valor económico en el mercado desde época tardorrepublicana (p.ej.: Mar et al. 2012: 73). A esta elección no debió ser ajena su geografía privilegiada, en un llano adecuado para la agricultura, emplazado entre los ríos Llobregat y Besòs, lo que facilitaba su comunicación con las tierras del interior, y al mismo tiempo una elevación natural para observación y control del litoral en Montjuic. Estos cambios se encuadrarían en el proceso de reorganización sistemática de la recién creada provincia Hispania Tarraconensis, con el objetivo fundamental de normalizar jurídicamente la situación de la Layetania, y responderían más bien a su deseo de situar política y administrativamente en el marco jurídico colonial a los ciudadanos romanos establecidos en la región (Guitart 1987: 148).

Paralelamente a la fundación, se producen una serie de cambios estructurales focalizados en la creación de la centuriatio, cuya estructura interna parece responder a la misma planificación que la territorial, así como la creación de una compleja red viaria (Palet 1997: 185). Estos cambios implican una ocupación del territorio, a su vez caracterizada por cambios en los patrones de asentamiento y su nueva ordenación y por lo tanto en la función económica y administrativa de la nueva colonia, fruto de la consiguiente deductio asociada a la fundación.

En estas páginas me centraré en los dos tipos de ánfora más representativos de la Tarraconense oriental, la Pascual 1 y la Dressel 3-2 (Dell'Amico y Pallarés 2007, López Mullor y Martín Menéndez 2008; Berni 2015a y 2017 para las Dressel 3-2), intentando relacionarlas en lo posible con Barcino, la protagonista principal de este estudio, aunque englobándolas en su contexto desde sus centros de producción (ab origine), siguiendo por su transporte marítimo (in transito) y acabando en su destinatario final, el consumidor (ad destinum).

\section{LA PRODUCCIÓN}

Los más recientes hallazgos, normalmente excavaciones de urgencia en el suburbium de la ciudad y en su ager, han puesto al descubierto estructuras productivas de vino y de fabricación de las ánforas para su envase y exportación (Granados 2001: 156-163, Carreras 2009a: 11-15 y fig. 1, Peña y Miró 2017).

\subsection{Estructuras productivas}

Según estos autores, se trata de villas suburbanas, verdaderos centros de producción y almacenaje de vino, activas desde época republicana, situadas en su mayoría en el llano y cuyos restos consisten en instalaciones de prensado de uva (torcularia), bases de decantación y áreas de almacenaje en su parte rústica (cella vinaria con almacenaje en dolia).

En el territorio de lo que será la colonia, conocemos las del monasterio de Pedralbes ( $2^{\mathrm{a}} \mathrm{mitad}$ del s. I a.C. a segundo decenio del siguiente siglo), Pont del Treball Digne de la Sagrera (niveles preaugusteos) y Hospital de la Santa Creu i Sant Pau (desde finales del s. II a.C. o principios del siglo siguiente). Con menos evidencias, Can Ricart y Estació de Foneria. De todas ellas, la mejor conocida y estudiada es la del Pont del Treball Digne (Alcubierre et al. 2014: 378-379), situada cerca del tramo de la vía Augusta y comunicada con Baetulo (actual Badalona). La construcción de la villa y los restos de una cella vinaria, con 11 silos y hoyos de 16 dolia, dispuestos en tres filas, se datan en niveles anteriores a Augusto.

Con la colonia fundada, durante las primeras décadas de su existencia contamos con la villa suburbana de Can Cortada (dos salas de prensado y restos de un torno), la villa de Sant Pau del Camp (dolia defossa y un pozo amortizado con ánforas Pascual 1 y Dressel 3-2, tal vez expresión de un centro productor anexo), la de Can Batllori (cella vinaria con dolia defossa y 12 dolia in situ y un depósito) y la de Sant Andreu Comtal (restos de plantación de viñas). Por su parte, la del Pont del Treball Digne sigue con la producción vinaria, destacando una instalación de prensado con dos prensas de viga, remodelada en época flavia.

Lógicamente, al no contar con instalaciones anexas para producir ánforas, es de suponer que el vino almacenado o fermentado en dolia se trasladara a los talleres cercanos para ser envasado en las primeras, en el caso de que se destinaran a su transporte por mar. 


\subsection{Centros productores de ánforas}

Una primera zona de posible producción anfórica ya anterior a la fundación colonial se localiza en la montaña de Montjuic y sus alrededores:

- Mare de Deu de Port/Nostra Senyora del Port: en las cercanías de la antigua línea de costa en época romana. Se trata de una villa con restos de termas y de hábitat, con una amplia cronología (s. II a.C. a IV d.C.), si bien en lo que se refiere a nuestro propósito probablemente estamos en época augustea. No se encontraron restos del horno, pero sí gran cantidad de desechos de tegulae y anfóricos, todos ellos de la forma Pascual 1, aunque sin marcas.

- Estadio de Montjuic: posible alfar, descubierto a raíz de las obras de reacondicionamiento de la montaña realizadas en 1929. Solo se conservan fotografías, mostrando un conjunto de silos y gran cantidad de fragmentos anfóricos de Pascual 1 y Dressel 3-2, y ocasionalmente Dressel 20 locales. Tampoco se documentan marcas.

- Cementerio del Sudoeste: asentamiento con abundantes restos anfóricos, ocupado desde el s. II a.C., sin más evidencias.

La segunda zona, ya en tiempos de la colonia, se articula en el actual barrio de la Ribera, a las afueras de la parte septentrional de la muralla, en las cercanías del litoral y de la vía Augusta. El suburbium norte de la ciudad formaba un auténtico barrio artesanal, que funcionó desde mediados del s. I a.C. hasta finales del s. II d.C. Conocemos alfares en las calles Princesa 21, Argenteria/Manresa, Montcada y Carders 5 y Mercado de Santa Caterina/Avinguda Francesc Cambó (Berni y Carreras 2001: 105-107, Carreras 2009a: 15-20 y fig. 4, Martínez Ferreras 2014: 109-146, Peña y Miró 2017: 14 y plano p 13) (fig. 1):

Tenemos informaciones más precisas de los siguientes:

- Avinguda Francesc Cambó: se documenta un depósito de 48 ánforas Pascual 1 y Dressel 3-2 y cenizas, que parecía continuar hacia el solar del convento de Santa Caterina y por lo tanto formaría parte de la misma alfarería.

- Mercat de Santa Caterina (Aguelo et al. 2006, Aguelo y Huertas 2009): vertedero de ánforas, con abundantes desechos de horno y piezas deformadas, aunque no se localizaron los hornos. Las ánforas son mayoritarias, destacando la Pascual 1 y en segundo lugar la Dressel 3-2. El abanico de la producción hay que situarlo entre los años 10-5 a.C. y 20
d.C. como mínimo y su momento final, como muy tarde, a mediados del s. I d.C. Contamos además con una serie de marcas, procedentes del lugar según Carreras (2009: 41-43). La caracterización arqueométrica de las arcillas muestra que las ánforas allí encontradas procedían del territorio de la ciudad, pero también de áreas cercanas, apuntando a su función también distribuidora. Estamos ante una industria urbana al servicio de las necesidades de los propietarios de los fundi cercanos o de la propia colonia (Martínez Ferreras et al. 2007: 117, Martínez Ferreras 2014: 124-146, fig. 62).

- Carrer de la Princesa 21 (Casas y Martínez Ferreras 2006, Casas 2009): a unos $100 \mathrm{~m}$ del anterior, se exhumó un horno de planta circular con pilar central, que conservaba el praefurnium y la cámara de combustión, destinado a cocer cerámica pero no ánforas por sus pequeñas dimensiones. Fabricaba cerámica común, tegulae y pondera. Sin embargo, en un vertedero se recuperaron 451 fragmentos de ánfora, de los cuales 52 de labios de Pascual 1 y 12 pivotes, tres de los primeros con defectos de cocción, y una pieza de perfil completo, de dimensiones más pequeñas que las habituales. Los fragmentos de Dressel 3-2 son minoritarios, aunque es posible que también se fabricaran allí. No se encontraron marcas. Datación del horno y vertedero: s. I d.C., sin más precisión.

- Carrer Montcada: al efectuar obras de remodelación del Museo Picasso se localizó un posible alfar, con gran cantidad de ánforas con algunas marcas y defectos de cocción. Atribuibles al alfar serían los sellos C, EPHI, QFS y LYA (Berni y Carreras 2001: 106-107 y n ${ }^{\circ} 7,11,14$ y 21). Las Dressel 3, muy primigenias, muestran acabados típicos de la Pascual 1 y se observa el proceso de cambio hacia el nuevo estándar de la Dressel 3 itálica (comunicación personal de P. Berni).

Contamos además en el mismo sector con una serie de vertederos que podrían indicar la proximidad de un centro productor: Plaça Comercial/Born, Argenteria/Manresa y Correu Vell, con altas concentraciones de ánforas tarraconenses, tanto locales como de otras zonas, especialmente Pascual 1 y Dressel 3-2 (Carreras 2009a: 18-20). En conjunto se ha propuesto una secuencia en cuatro periodos, desde el 10 a.C.-10 d.C. al 40-60 d.C., diferenciando al mismo tiempo las pastas, secuencia que sería la de funcionamiento de estas alfarerías (Carreras 2009b: 41-44).

Así pues, los tipos anfóricos fabricados en estos establecimientos son la Pascual 1 en los años 


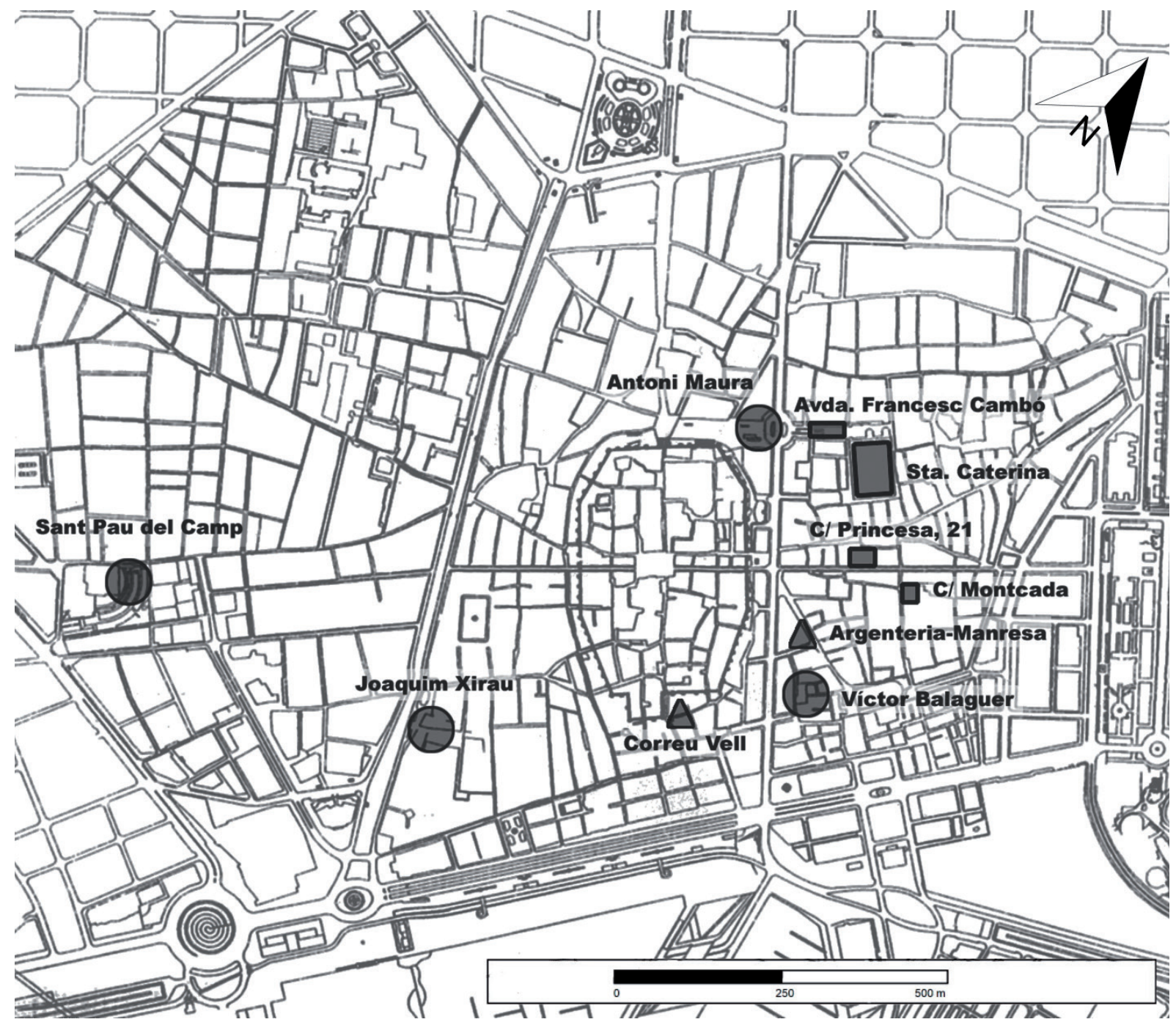

Figura 1. Localización de alfarerías y lugares de hallazgo de los sellos en Barcino (a partir de Carreras 2009b: fig. 5, según J.M. Puche, ICAC).

anteriores a la fundación, a la que se suma la Dressel 3-2 que la va desplazando, siendo mayoritaria en los años finales del reinado de Augusto y sobre todo con Tiberio. Hemos sugerido situar ese momento inicial durante la última década antes del cambio de era, unos años más tarde de la fundación de la colonia (Berni y Miró 2013: 76). La hipótesis se basa en el hecho de que las primeras industrias del extrarradio oriental de la ciudad (Solar del Mercat de Santa Caterina, Carrer Princesa $n^{\circ} 21$ ) continuaron fabricando ánforas Pascual 1 (Aguelo et al. 2009, Casas Blasi 2009, Carreras 2009a). Es importante resaltar la ausencia de ánforas Tarraconense 1 en estos vertederos suburbanos, lo que sería un indicio de su desaparición y sustitución por la Pascual 1 en fechas anteriores a la fundación de la colonia.

Pero al poco tiempo se introdujo el patrón de la Dressel 3, que copiaba el estándar de su homóloga itálica, a la cadena productiva de la Pascual 1, como hemos podido observar con el material anfórico del Carrer Montcada, donde se aprecia con claridad el primer intento de imitación por las formas de bordes, pivotes y asas (Berni y Carreras 2001: 115, Carreras 2009b: 25).

La caracterización arqueométrica efectuada en dos de estos centros (calle Princesa y Mercat de Santa Caterina) indica una composición distinta (Martínez Ferreras et al. 2007: 116-117; Martínez Ferreras 2014: 282): la pasta cerámica del primero es homogénea, 


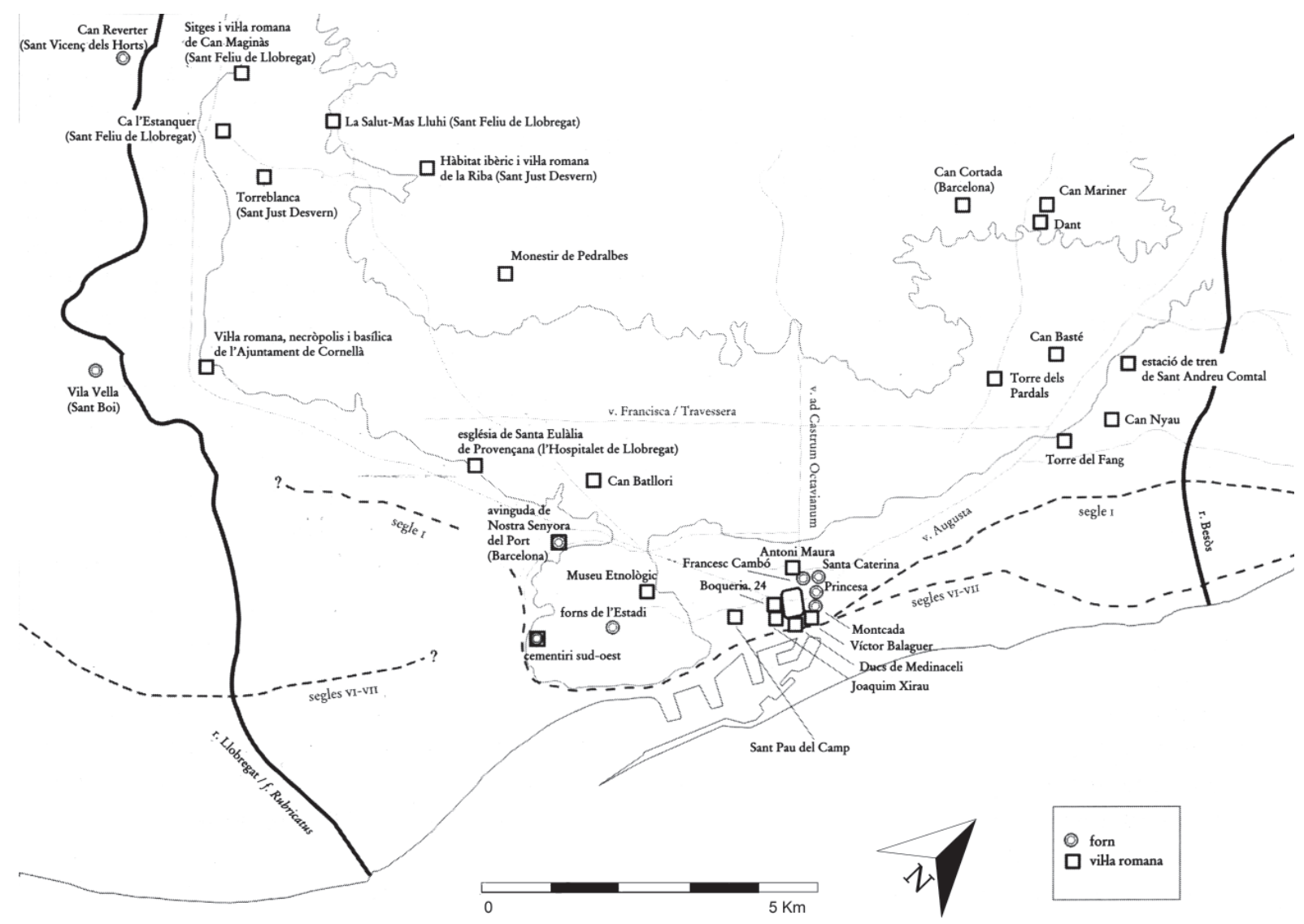

Figura 2. Alfares y villae en el territorio de Barcino (a partir de Carreras 2009a: fig. 1, según J.M. Puche, ICAC; reconstrucción topográfica según J.M. Palet 1997: fig. 46).

fácilmente diferenciable en cuanto a su composición y muy estandarizada, mientras que la del Mercat se caracteriza por una gran variabilidad y en algunos casos, es similar a las de los complejos alfareros del suburbium de Badalona (Can Paixau e Illa Fradera), hasta el punto de que en ocasiones no se puede asegurar que algunas piezas procedan del lugar, sino de su ager y nos encontraríamos en un punto de redistribución.

En conjunto, un primer estudio de los sellos (Berni y Carreras 2001: 103-104) incluía 60 marcas, 48 de ellas en ánforas tarraconenses, aunque solo 16 podían atribuirse a los talleres del Pla de Barcelona. Un trabajo posterior (Carreras 2009b) aumentaba esta cantidad a 27, en tres períodos, desde el 10 a.C.-10 d.C. hasta el 15-20 d.C. (fig. 2).

Por su parte, el polígono industrial avant la lettre del Baix Llobregat, con el que Barcino estuvo estrechamente ligada ya desde su fundación, distribuido a lo largo de unos $10 \mathrm{~km}$ por las dos orillas de la desembocadura del río, está formado por Sant
Boi de Llobregat, Sant Vicenç dels Horts, Can Tintorer y Can Pedrerol (Berni 2015b, Carreras 2015). Hay que considerar la dinámica observada en este complejo, pues su actividad se inicia en la parte cercana al delta (Sant Boi y Sant Vicenç dels Horts) y no está vinculada a centros de productos vinícolas. Son zonas industriales destinadas a cubrir las necesidades de envasar y almacenar vino no solo de su territorio, sino también de la periferia del ager de Barcino, y de recepción del vino envasado en otros recipientes, como odres, de las comarcas del interior de la Layetania y llegado por la vía del Llobregat. Su navegabilidad en época romana está constatada, al menos hasta el "Pont del Diable", en la mansio de Ad Fines (Martorell) (Izquierdo 2000, Berni 2015b: 56). La zona de Sant Boi ya fue romanizada en época tardorrepublicana y su actividad vitivinícola ya existe hacia el 30 a.C. (Berni 2015b: 58).

Con la fundación de Barcino y la consiguiente distribución de tierras entre los colonos, aparecen nuevos 
alfares, ahora sí vinculados a centros de producción agrícola más al interior, como Can Tintorer y Can Pedrerol, que inician su producción hacia 10-20 d.C. y de donde hemos visto que proceden la mayoría de los sellos de Dressel 3-2 recuperados en pecios; por lo tanto, esta sería la zona de origen de estos transportes (Carreras 2013: 346) (fig. 3). Se inicia así la expansión hacia el interior, bajo el control de las élites de la colonia, siendo la economía del vino un negocio lucrativo y dinamizador para el crecimiento económico de la ciudad (Berni 2015b: 56). Al mismo tiempo, se contribuyó a descentralizar y exportar unos excedentes de vino cuyo origen está en la vertiente oriental de la región, desde la segunda mitad del s. I a.C. (Berni y Carreras 2001: 104).

El interés común de estas localidades en el negocio del vino resulta evidente por una serie de circunstancias coyunturales: el potencial arqueológico de las instalaciones industriales y sus vertederos, su funcionamiento en paralelo con las últimas ánforas Pascual 1 y con la fabricación de Dressel 3-2, y la movilidad de ciertos personajes que aparecen en los sellos, que se encuentran en los cuatro talleres, haciendo uso de diferentes punzones, muchas veces asociados entre ellos y sin un orden jerárquico o de precedencia (Berni y Miró 2013: fig. 15). Así pues, como iremos viendo al hablar de los pecios de Dressel 3-2, las ánforas del Baix Llobregat se exportaban juntas en navíos por rutas de larga distancia.

Por lo que se refiere al final de estas producciones, los centros de los que tenemos datos no van más allá del s. II d.C. (Carrer Carders y Mare de Deu del Port, primeras décadas del siglo I, hasta mediados de este siglo los de la calle Montcada y Santa Caterina, y el de la calle Princesa hasta finales del s. II). Ello no implica, sin embargo, el fin o la disminución de estas producciones vitivinícolas, pues instalaciones parecidas se registran tanto intramuros como en el ager, sino un cambio tanto de las estructuras productivas vinarias como de mercado, más orientado al abastecimiento regional; y por otra parte, también en la forma de envasar el vino, sea en otro tipo de ánforas o en recipientes perecederos tipo odres o toneles (Peña Cervantes 2010: 166-167, Peña y Miró 2017: 14-16).

\section{LOS PUERTOS DE BARCINO}

El primer embarcadero lo encontramos en la montaña de Montjuic, que ofrecía no solo un excelente refugio natural a los temporales de levante y septentrionales, sino también en buena medida a los de la vertiente del Llobregat. En la de poniente, en Nostra Senyora del Port, se localizó un poblado ibérico y una treintena de grandes silos para cereales, amortizados entre los siglos IV y III a.C. (Asensio et al. 2009: 71-72. Su abandono debido a la colmatación por los sedimentos se data probablemente a finales de la República y, en consecuencia, su posible traslado a la ya creada Barcino (Izquierdo 2009: 185).

Al menos desde el s. IV a.C. hasta la Edad Media existió, en lo que ahora es el delta del Llobregat pero que en época antigua fue estuario, una zona estratégica de fácil acceso al interior por el río, relativamente protegida de los temporales pero expuesta a los de levante, que se usó como embarcadero. Se trata de Les Sorres, donde desde finales de la República se detecta la llegada de vino itálico en ánforas y posteriormente la salida de las exportaciones locales de vino layetano envasado en ánforas del Baix Llobregat, cuyos hornos se encuentran en las proximidades (Izquierdo 2009 y 2013). En relación con el tema que aquí nos interesa, como veremos más adelante, se encontraron los restos de nueve pecios (Izquierdo 2013: 313-314). Nos encontramos, pues, ante una importante ocupación agraria romana de lo que será el territorio de la ciudad ya antes de su fundación, orientada muy probablemente a la producción vitivinícola y a su exportación marítima.

La creación de la ciudad por Augusto debió implicar una serie de cambios estructurales del territorio en época altoimperial (Palet 1997: 166-177) en las vías de comunicación existentes y en la creación de otras nuevas, como la vía Augusta. En el caso de las comunicaciones marítimas, la construcción de un puerto lo más cerca posible de la población debió verse necesaria, sea aprovechando las características de la costa para este fin o de nueva creación. Ahora bien, la configuración del litoral ha cambiado desde época romana (Riba y Colombo 2009) y la arqueología ha puesto de manifiesto que la costa llegaba al menos hasta el actual Passeig del Born. Las necrópolis del Born y de Santa Maria del Mar ("Santa Maria de les Arenes") (Beltrán de Heredia 2010) lindaban en la Antigüedad Tardía con la playa, pues muchas tumbas se excavaron en la arena.

Si nos situamos en la Puerta Decumana o Puerta de Mar, llama la atención el Castell de Regomir (castellum), sobresaliendo de la estructura de la muralla, con probable función defensiva y de control de la zona, justo donde llegaba el mar. Con anterioridad a la edificación de la muralla Bajo Imperial, durante el último cuarto del s. I a.C. fue construido un sector público y monumental, compuesto por una estructura absidal de 


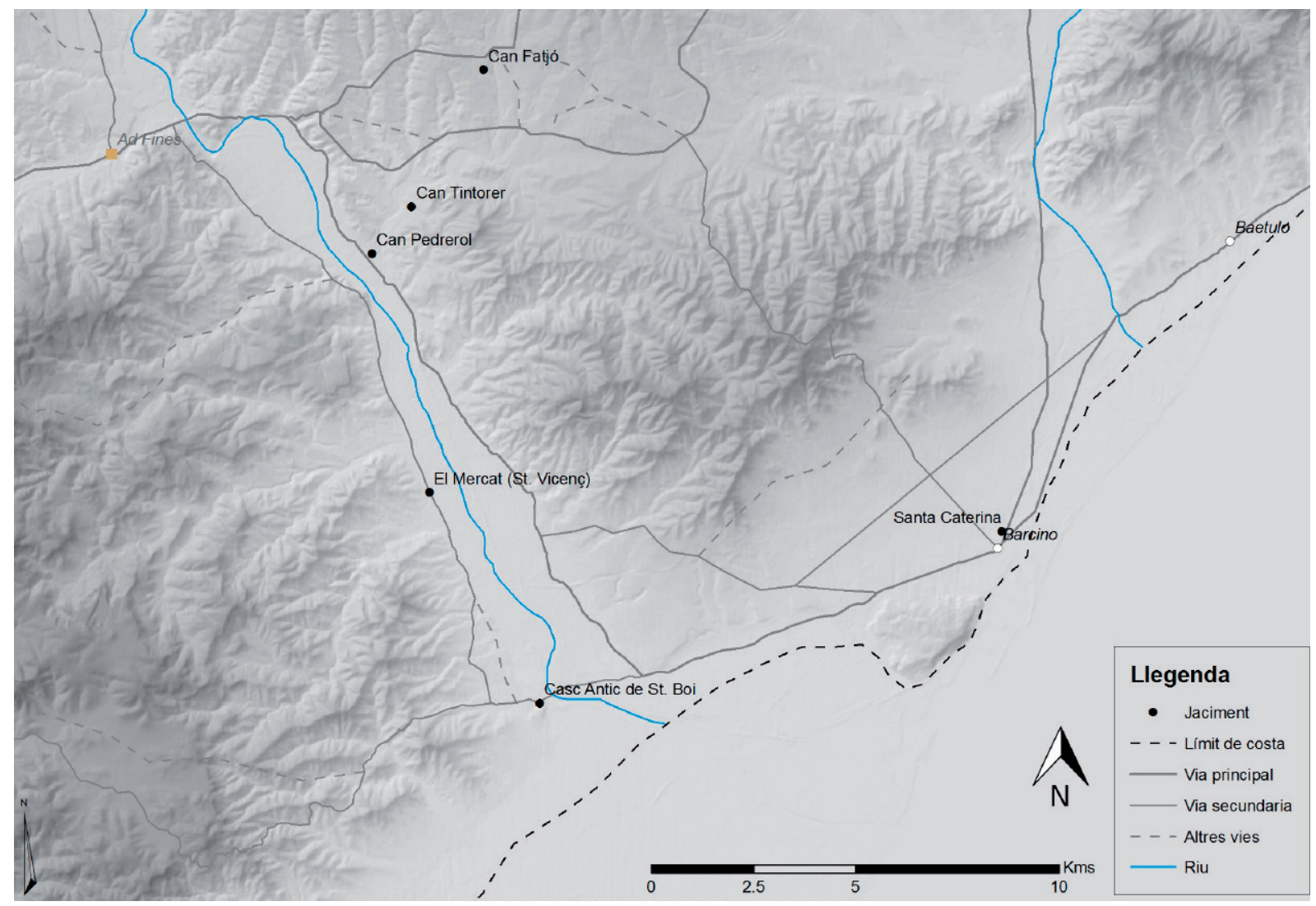

Figura 3. Localización de los alfares del Baix Llobregat (a partir de Moret et al. 2013: fig. 5).

incierta función, tal vez unos baños públicos, un criptopórtico y un área enfrente del Decumanus Maximus dedicado posiblemente al almacenaje y a tabernae o a un pórtico (Hernández-Gasch 2006: 87-89 y fig. 4.1). Así pues, es muy posible que se trate de horrea, al lado de un pórtico y/o de tiendas, que sin duda alguna hay que relacionar con el establecimiento portuario que se hallaba en sus proximidades. Desde la puerta oriental, actual Plaça de l'Angel, excavaciones realizadas en las calles Argenteria y Manresa permitieron localizar una vía romana del s. I d.C. que llevaba al mar (Casas Blasi 2009: 65-66) (fig. 4).

En resumen, tenemos indicios para pensar que, ya desde su fundación o poco después, Barcino contaba con una infraestructura portuaria ex novo para dar salida a los productos de la región, como el vino envasado en las ánforas fabricadas en los alfares de su suburbium alrededor del barrio de la Ribera, pero también a las ánforas del Baix Llobregat, transportadas hasta allí por barcazas. Y ello no solo a efectos prácticos y logísticos, sino también para pasar los controles fiscales y aduaneros inherentes a estas exportaciones. Entramos aquí en otro terreno, el de la consideración de Barcino como un núcleo de centralización del almacenamiento, de fiscalización y posterior exportación de estas mercancías y con ello de su función como lugar de recaudación del portorium, el impuesto de carácter público y regular que gravaba, entre otros, las mercancías en el puerto. En nuestro caso era la quinquagesima o $2,5 \%$ del total del producto y para su cobro se debía contar con las debidas instalaciones portuarias. Se conocen ocho en Hispania, casi todas en la Bética y probablemente existió también una en Tarraco (Izquierdo 2009: 183, Járrega 2011: 97, Terrado Ortuño 2019: 266-272).

Por la epigrafía de Tarraco conocemos la existencia de la praefectura orae maritimae. En una de las inscripciones, se trata del praefectus orae maritimae conventus Tarraconensis con sede, podemos pensar, en Tarraco (RIT 162). Por otra parte, Q. Licinio Silvano Graniano (RIT 288 y 289), bien conocido entre la aristocracia de Baetulo, es citado como prefecto de la ora maritimae Laeetanae y él mismo o su hijo aparece como patrono de Baetulo, según una inscripción del año 98 d.C. (Guitart 1976: 31-32, Terrado Ortuño 


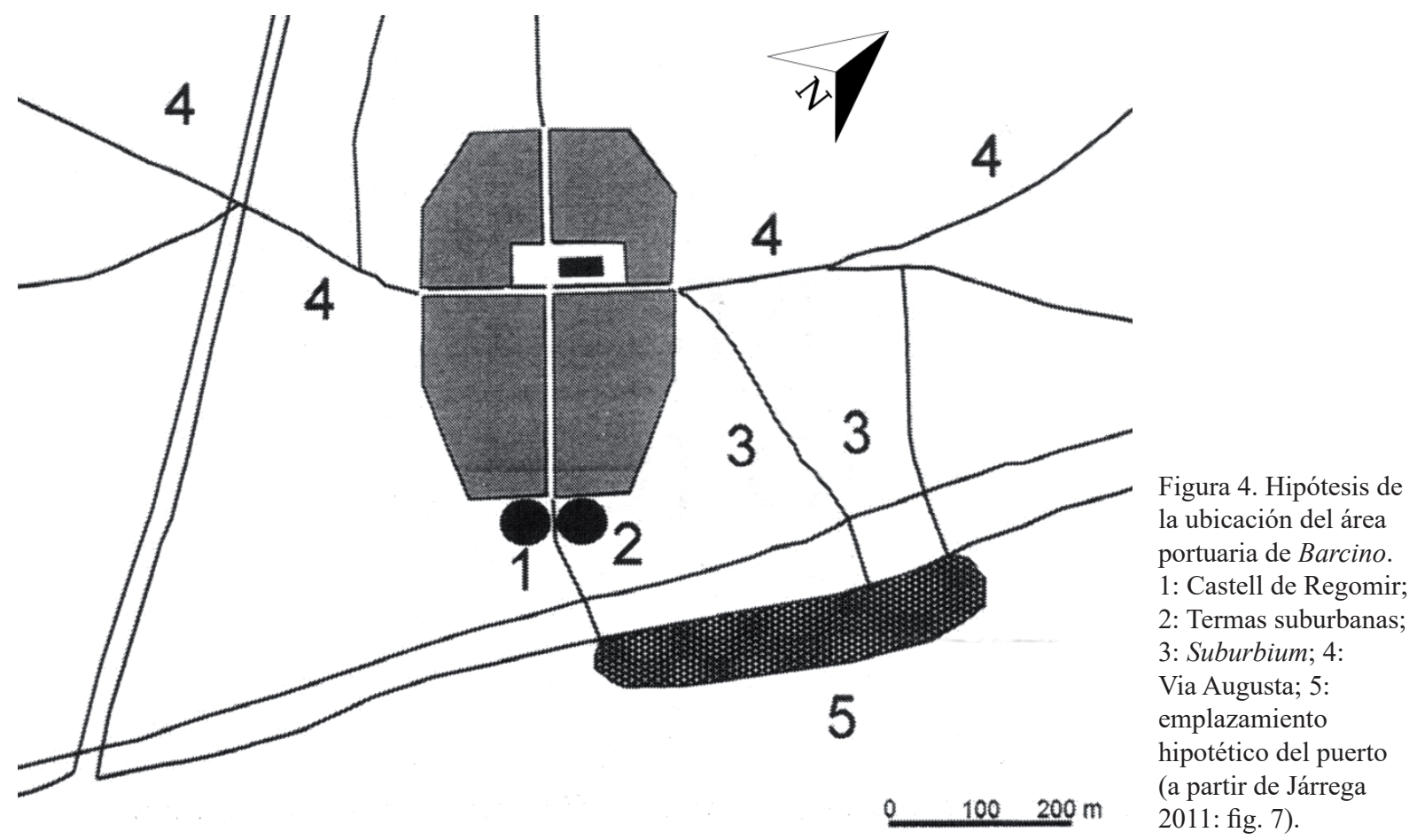

2019: 269). Este cargo tendría también funciones militares y podemos pensar que se ejercería compartida con Barcino, donde estarían instalados la totalidad o parte de los soldados (Izquierdo 2009: 183-184, Járrega 2011: 99-101).

No obstante, estas inscripciones se datan, según los autores, en los s. I-II d.C. o con Vespasiano (Terrado Ortuño 2019: 266). La prefectura de la ora maritimae de la Layetania parece haberse instituido en época flavia, como parecen indicar las inscripciones (Járrega 2011: 105), cuando se construye también el edificio de la puerta de Regomir. Pero es precisamente en época flavia cuando empiezan a decaer las exportaciones vinarias en ánforas Dressel 2 layetanas (vide \# 4.2) mientras que, sin embargo, se produce la eclosión de las inscripciones honoríficas del forum y cobran importancia las élites locales, a las que relacionamos con este comercio (vide \# 5.1). Por lo tanto, estaríamos ante una reestructuración de estas o de otras actividades económicas y comerciales, no ante una decadencia.

En consecuencia, no podemos asociar el portorium ni la prefectura citada con la época que aquí nos interesa, pero lo que parece claro es que existía en Barcino un portus, con una determinada estructura, para diferenciarlo de la statio, un simple fondeadero para intercambio de mercancías (Járrega 2011: 85-86 y 105). Debió seguir en actividad durante la Antigüedad Tardía, pues siguen llegando importaciones en ánforas, sobre todo africanas y del Mediterráneo oriental (Járrega 2011: 108).

\section{LOS CIRCUITOS COMERCIALES}

Pasando a la siguiente etapa de estas actividades, examinaremos la difusión de este comercio vía marítima, y por lo tanto, nos centraremos en los pecios cuyo cargamento principal esté formado por ánforas de la Tarraconense oriental. Disponemos de dos inventarios. El primero fue publicado por Liou (1987) (fig. 5), en el que se referenciaban once de Pascual 1 y catorce de Dressel 3-2. El segundo es el de X. Nieto y X. Raurich (1998). Más recientemente, C. Carreras (2013) hizo un reestudio de los mismos con la información aportada por los sellos de los hornos del Baix Llobregat, cuyo lugar de embarque de estos barcos estaría en esta zona.

\subsection{Pecios con cargamento de Pascual 1}

\subsubsection{Pascual 1. Introducción}

Hacia 35-30 a.C. podemos situar la aparición de esta ánfora como un estándar propio de la Layetania, de diseño innovador y único, optimizado funcionalmente. 


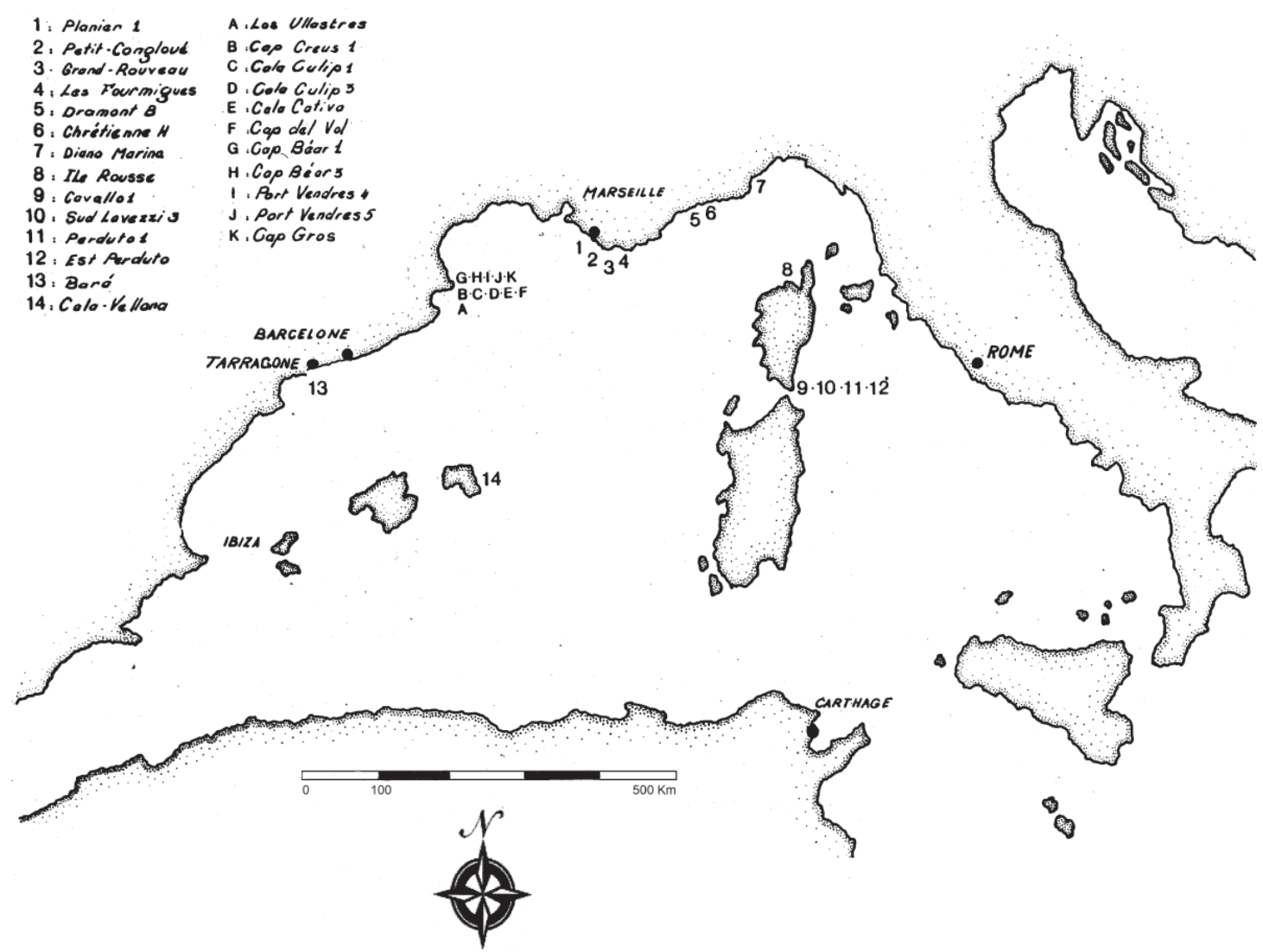

Figura 5. Mapa de situación de los pecios con cargamento de Pascual 1 (A-K) y Dressel 3-2 (1-14) de la Tarraconense (a partir de Liou 1987: fig. 1).

Es un ligero y excelente contenedor de vino para el transporte por mar, producto del éxito y consolidación del modelo económico anterior, representado por la Dressel 1 citerior y la Tarraconense 1 (Pascual 1962, López Mullor y Martín Menéndez 2008: 698701) (fig. 6).

A partir de la difusión de las Pascual 1 en la Galia, se observa que el oeste y el sur del país fueron sus mercados más importantes (Miró 1988: 126-133) y Narbo Martius (Narbona), su receptor y distribuidor principal vía Aude-Garonne (una síntesis reciente: Laubenheimer 2015: 187-189; también Sánchez 2015 para la región de Narbona). Este comercio continuaba vía marítima hasta Britannia, aunque fue mucho menos importante (Miró 1988: 139, Etienne y Mayet 2000: 218-223, López Mullor y Martín Menéndez 2008: 701). Al este existió otra ruta por los ríos Rhône-Saöne-Rhin (Miró 1988: 133139, González Cesteros 2015, Laubenhemier 2015:
184-187), aunque las ánforas tarraconenses llegan en pocas cantidades y es el ánfora de base plana Oberdaden 74 la más representada (González Cesteros 2015: 210-2122, González Cesteros y Berni Millet 2018: 22 y 34-36). También se documenta en Ostia/Roma, pero en muy escasas cantidades (Hesnard 1980: 145-146, Rizzo 2014: 198 y tabla 27, Olcese et al. 2017: fig. 3, Rizzo 2018: fig. 4). Finalmente, en Cartago su presencia es también mínima (Miró 1988: 142, Berni y Miró, en prensa).

\subsubsection{Pecios}

De algunas décadas anteriores a la fundación de Barcino son los pecios con cargamento mixto bético-tarraconense de ánforas Tarraconense 1 de Cala Bona (50-30 a.C.) e Illes Formigues (40-30 a.C.), ambos en la Costa Brava 


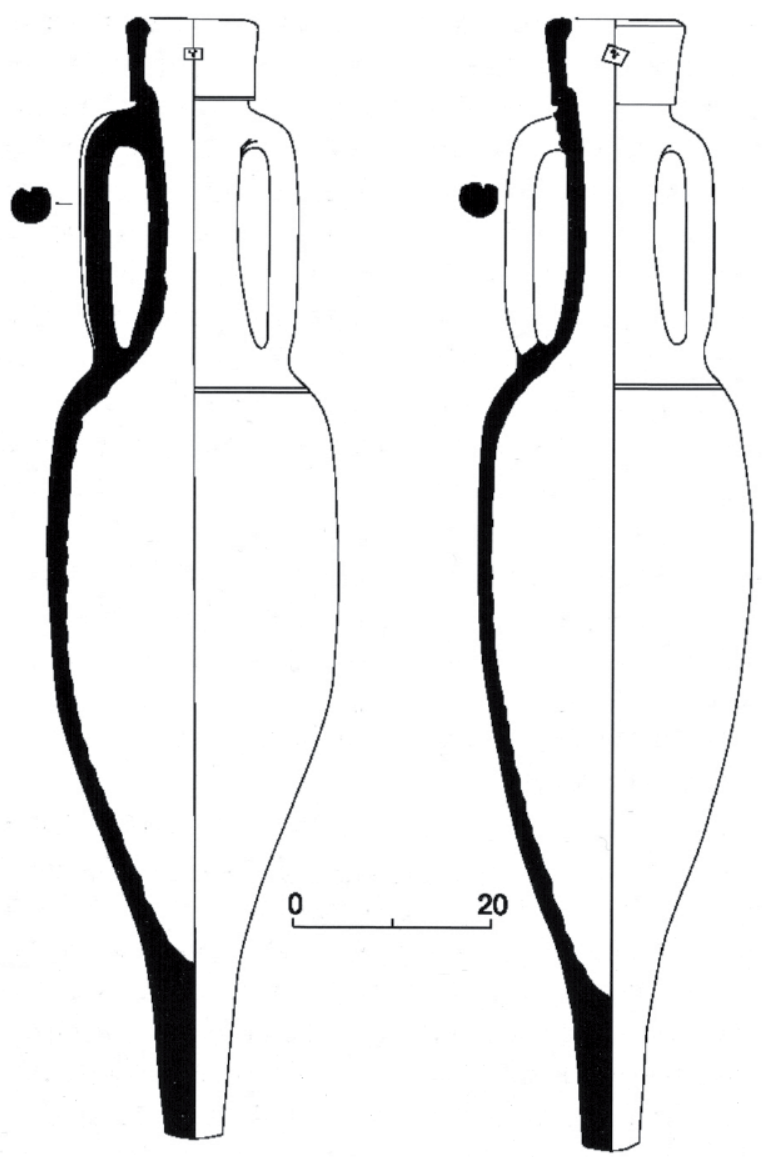

Figura 6. Ánforas Pascual 1 del pecio de Els Ullastres según F. Foerster y R. Pascual (López Mullor y Martín Menéndez 2008: fig. 8.2 y 8.3 ).

(Martín Menéndez 2008), de hecho, las primeras exportaciones de vino layetano, en el caso muy probable de que este fuera su contenido (Miró y Járrega 2018 y 2019).

Pasando ya a cargamentos de Pascual 1 de este mismo periodo, conocemos los de Cap Béar 3 (5030 a.C.) (Liou y Pomey 1985: 547-551, Colls 1986) y Port-Vendres 4 (40-30 a.C.) (Colls et al. 2015, Martínez Ferreras et al. 2015). Se trata de actividades diversificadas, descentralizadas, con cargamentos heterogéneos (tarraconenses o layetanos, itálicos y béticos), expresión de un comercio de redistribución. Predominan los sellos del Maresme y probablemente en Iluro (actual Mataró) habría que situar el puerto de embarque, dada la importancia de esta zona septentrional de la comarca como foco temprano de romanización y de producción anfórica y vinícola (Martín y García 2007). Destacamos la marca LICIN(ius) de Cap Béar (Colls 1986: fig. 41.15).
En el inventario de B. Liou sobre los pecios de Pascual 1 (Liou 1987: 271-274), seis están en la costa gerundense y cinco en la zona de Port-Vendres (Pyrénées-Orientales), pero solo de cinco de ellos contamos con un mínimo de información válida. El otro inventario (Nieto y Raurich 1998: 115-119 y tabla 2), contabiliza 15 pecios, todos hundidos entre Arenys de Mar y Narbona. Este hecho indica perfectamente la ruta de navegación y el principal puerto de destino. Por su parte, R. Etienne y F. Mayet (2000: 239-241) catalogan 15 pecios estudiados: sobresalen seis en Cadaqués/Cap de Creus y cinco en Port-Vendres. Cuando es conocida su estructura, se trata de naves de cabotaje de pequeño tamaño y carga: 13-14 metros de eslora para Cap del Vol y Els Ullastres, 22-24 toneladas de desplazamiento y capacidad de 550600 ánforas, equivalentes a unos 12000-13000 litros. Están adaptados para una navegación mixta por mar y aguas fluviales poco profundas (Parker 1992: n 186 y 1192, Nieto y Raurich 1998: 122, Vivar y Geli 2015:1819). Si el destino final no ofrece dudas, el puerto de partida resulta problemático. En cuanto a las fechas del hundimiento, sería el último cuarto del s. I a.C. para Els Ullastres y entre 10 a.C. y 5 d.C. para el Cap del Vol (Martínez Ferreras et al. 2013: 70) (fig. 7).

Para su ruta de navegación, es de costos limitados pues el tipo de nave no requiere una infraestructura portuaria importante. Un embarcadero con una sencilla estructura de almacenaje y transporte en la nave sería suficiente. No haría falta escala alguna, como Ampurias, que en cualquier caso podría ser una parada técnica antes de pasar el peligroso Cap de Creus, y el viaje entre ambas ciudades duraría unas 14 horas (Nieto y Raurich 1998: 126-127).

Los sellos presentes en las ánforas, tanto en Els Ullastres (A, F, H, P y T) como en Cap del Vol (A, C, D, F, G, H, I, IVLI THEOPHIL, L, MPORCI, QFS, S, T, V y VAS) indujeron a Carreras y Berni (2002: 360361) a plantear su posible lugar de embarque en Barcino o cercanías para el primero y Barcino o Baetulo para el segundo. Para ello, partieron de la base de que las ánforas de los alfares del Baix Llobregat y del Vallès Occidental se cargaron en Barcino para el caso de Els Ullastres y lo mismo para el Cap del Vol, aunque en este, por la presencia de algunos sellos capitalizados por Baetulo (L, MPORCI y VAS), el barco habría podido efectuar una escala allí.

En publicaciones posteriores, también basándose en los sellos, uno de estos autores (Carreras Monfort 2013: 340-341) relaciona un catálogo de doce pecios (tres de Pascual 1 y el resto de Dresel 3-2) con posible procedencia en el delta del Llobregat. El del 
Cap del Vol llegaría desde el delta a Barcino, donde cargaría las producciones de los alfares de Santa Caterina y Carrer Montcada, y seguiría hacia Baetulo (donde llegaban las producciones del Vallès vía fluvial), y el cargamento sería completado. Sin embargo, los análisis en muestras de diecinueve Pascual 1 de Els Ullastres y veinte del Cap del Vol, realizados después de estas publicaciones, indicaron que la mayoría de las ánforas de ambos pecios proceden de un mismo lugar, que hay que situar en la parte baja del valle del río Besòs. Treinta y cuatro de ellas pueden ser atribuidas a un solo centro de producción en las proximidades de Baetulo, desde donde se iniciaría el viaje de ambos barcos, mientras que otro conjunto es compatible con dos talleres al norte del Maresme, posiblemente Iluro (Martínez Ferreras et al. 2013: 77). No obstante, si de los sellos A, C, QFS y S, atribuidos hipotéticamente por Carreras y Berni (2002: 365) al taller de la calle Montcada de Barcino, presentes en Cap del Vol y la A en Els Ullastres, se confirmara su origen barcelonés, existiría la posibilidad de que este fuera el origen de la ruta. La cuestión debe quedar, pues, abierta, a la espera de nuevas investigaciones.

Finalmente, tenemos el pecio Port-Vendres 5 (1-20 d.C.), con un transporte mixto de Pascual 1 y Dressel 3 de la Tarraconense, que constituye un caso aparte y único de transporte marítimo entre la Tarraconense y la Galia Narbonense (Martínez Ferreras et al. 2014). Se recuperaron fragmentos atribuibles a un número mínimo de ciento cuarenta y ocho Pascual 1 y once Dressel 3, además de ocho ánforas de otra tipología, que podrían formar parte tanto del cargamento como de los utensilios de a bordo, además de cinco placas de mármol de Carrara (Martínez Ferreras et al. 2014: 111).

Nos encontramos ya en unos años en que ha hecho su aparición la Dressel 3 (Berni 2017: 219-221) y con toda probabilidad se trata de una primera exploración del mercado del vino envasado en estas ánforas. Los análisis petrográficos de veintiseis ánforas permitieron distinguir hasta siete fábricas. Los grupos mayoritarios podrían atribuirse a talleres de Baetulo e Iluro o sus proximidades y el tercero tiene cierta similitud con las producciones del sector meridional catalán (Martínez Ferreras et al. 2014: 119-120). A la vista de la desproporción a favor de la Pascual 1, si estas analíticas fueran generalizables, podemos deducir que la ruta podría haberse originado en Baetulo, donde se cargó casi en su totalidad el barco, haciendo escala en Iluro para completar la carga. Para ello partimos de la base de que estos centros urbanos portuarios funcionaron como centros de concentración y redistribución de

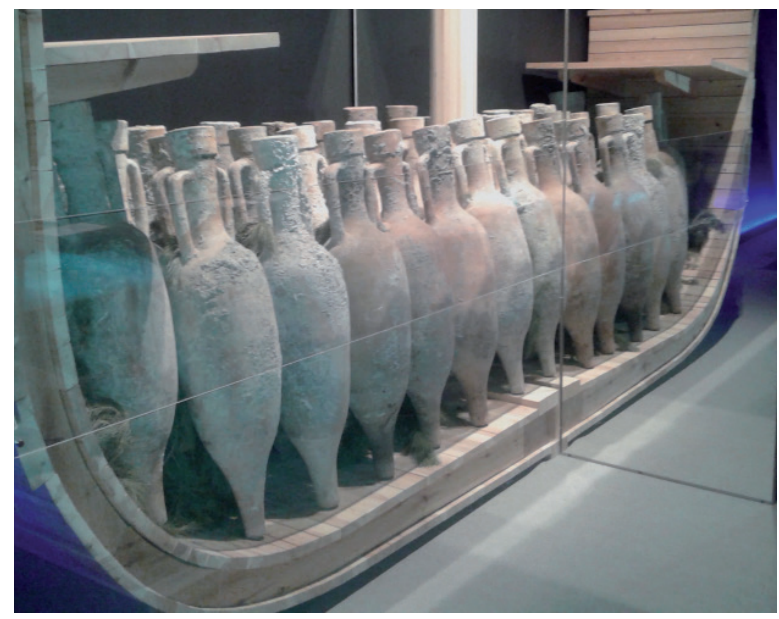

Figura 7. Ánforas Pascual 1, estibadas en la nave (exposición en el Museu d'Arqueologia de Catalunya, abril 2017) (foto del autor).

envases procedentes del territorio cercano. Otra posibilidad es que se tratara de una ruta directa, en la que el barco hubiera partido de un solo centro, donde se habrían cargado tanto las ánforas como las placas de mármol (Martínez Ferreras et al. 2014: 121-122).

A estas informaciones de contextos in transito, podemos añadir las proporcionadas ad destinum, en Narbona y Lattes/Lattara (puertos de recepción primario y secundario, respectivamente), gracias al hallazgo de 58 ánforas Tarraconense 1 y Pascual 1, de varios contextos arqueológicos, siendo las segundas mayoritarias (Martínez Ferreras 2012). El análisis petrográfico de las mismas indica que en un primer momento (50-25 a.C.), las ánforas proceden mayoritariamente de centros de producción del Maresme septentrional, es decir, del territorio de Iluro. Durante el cuarto de siglo siguiente, en época de Augusto, se diversifica la procedencia, añadiéndose las producciones del curso bajo del Besòs, en las cercanías de Baetulo y Barcino. Aunque los talleres al sur de Barcelona están poco representados, sí lo está en Lattes el de Sant Boi de Llobregat y en ambos sitios el del Collet (Sant Antoni de Calonge, Girona), lo que sería la expresión en el último caso de la existencia de una escala más al norte de la Layetania. Finalmente, las producciones de Tarraco están ausentes. Resumiendo, en estas exportaciones galas, se constata la participación gradual de diversas comarcas layetanas, destacando Iluro en el primer momento y diversificándose en época de Augusto, participando las tres ciudades layetanas, además de las cuencas bajas del Besòs y del Llobregat (Martínez Ferreras 2012: 522-523). 

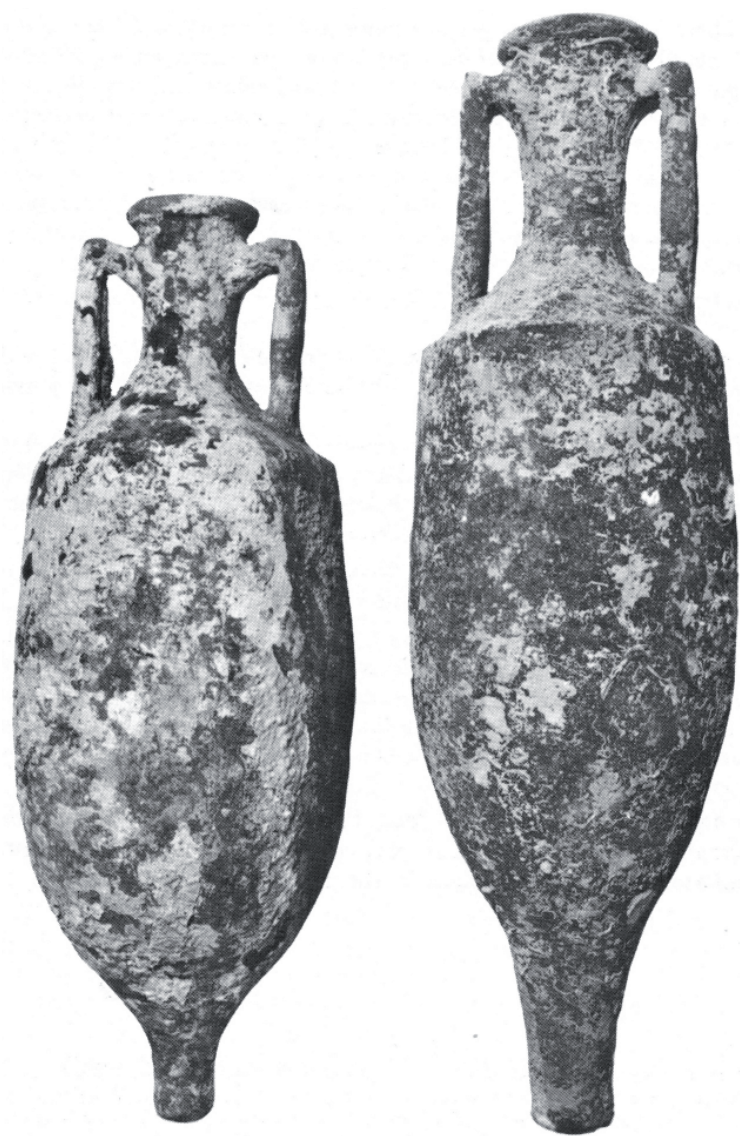

Figura 8. Dressel 3 del pecio Sud-Lavezzi 3 (izda.) y Dressel 2 del pecio Petit-Congloué (sin escala indicada) (CorsiSciallano y Liou: 1985 fig. 126).

Els Ullastres y Cap del Vol son la expresión de un comercio con cargamento homogéneo de vino envasado únicamente en ánforas Pascual 1 del Maresme, del Baix Llobregat y de Barcino, más centralizado y organizado. Estamos ya en el último cuarto del s. I a.C. y primera década del siguiente, cuando ya existía Barcino y donde tal vez haya que ver ya la función organizativa y centralizadora de la colonia. El primer punto de embarque no está claro, podría ser Les Sorres (alfarerías de Sant Boi, Sant Vicenç dels Horts), siguiendo por Barcino, donde se cargarían en la zona portuaria próxima a la puerta de Regomir o Baetulo, de donde proceden la mayoría de las ánforas, con posible escala en Iluro. Queda por dilucidar, en resumen, cuál de las dos ciudades actuaría como origen de la ruta y de embarque de sus producciones y de recepción de la otra, para ser embarcadas ambas.

La nave de Port-Vendres 5, cuyo viaje se inició probablemente en Baetulo, podría representar una etapa de transición entre los cargamentos homogéneos de
Pascual 1 y los de momentos posteriores, formados por Dressel 3-2 y dolia. El cargamento principal son las Pascual 1, el secundario las Dressel 3 y constituye un testimonio único de cargamento de ambos envases (Martinez Ferreras et al. 2014: 111). Estas últimas tal vez sean como un "muestrario" de un nuevo estándar layetano para introducir vino en el mercado galo.

\subsection{Pecios con cargamento de Dressel 3-2 y dolia}

Las exportaciones en Dressel 3-2 de la Tarraconense presentan unas características totalmente nuevas: cargamento homogéneo, muy especializado, compuesto casi exclusivamente por estos envases, a veces solos y otras compartiendo carga de vino en dolia. Son verdaderos buques-cisterna, con destino final en Ostia/Roma (Corsi-Sciallano y Liou 1985, Liou 1987: 274-277, Nieto y Raurich 1998: 119-127, Marlier 2008, Marlier y Sciallano 2008, Dell'Amico y Pallarés 2011). Excepcionalmente, uno de ellos (Cala Vellana, Menorca) tal vez se dirigiera a Cartago (rutas 7 y 14 de P. Arnaud para la navegación a vela: Arnaud 2005: 154-155, mapa) y del de Barà (Tarragona), probablemente procedente del ager de Tarraco, poco es lo que sabemos (Berges 1970) (fig. 8).

Este tráfico se efectuaba en un doble sentido, con exportaciones de vino itálico hacia el Mediterráneo occidental, pues conocemos pecios de Dressel 2-4 itálicas y dolia (p.ej.: Gianfrotta y Hesnard 1987, Marlier 2008, Dell'Amico y Pallarés 2011). Este negocio estaba capitalizado por la familia de los Pirani, radicados en Minturno, que marcaban los dolia (Corsi-Sciallano y Liou 1985: 169-171), lo cual implica una infraestructura particular de almacenaje, envasado y trasvase del contenido a la salida y la llegada (armadores, mercatores, etc.). Son naves semejantes algo mayores que las que transportaban las Pascual 1, aunque no mucho más, al menos cuando son conocidas (entre 18-22 metros de eslora y carga entre 45-50 toneladas) (Marlier 2008: 172, Sciallano y Marlier 2008: 149).

Estamos pues ante un cambio radical en la estructuración de este mercado, cuando el vino layetano envasado en Pascual 1 deja de exportarse a la Galia, al producir esta el suyo propio para su consumo y dejar de ser rentable (p.ej.: Laubenheimer 2015: 190). El cambio de envase también debió de implicar el cambio de calidad del vino en él contenido, de ruta y de destinatario; en definitiva, se trataría de una adaptación a las nuevas circunstancias económicas y comerciales del Mediterráneo occidental. La Dressel 3 
layetana copia de sus homólogos suditálicos, y se presenta como un envase alternativo a la Pascual 1 para la reconversión del negocio del vino a grandes mercados consumidores. Sin embargo, no representó un avance tecnológico original, como lo fue la Pascual 1, sino la adaptación del envase más representativo a la nueva coyuntura del negocio del vino, modificando levemente la morfología del ánfora para cumplir con un nuevo estándar. Su producción, como la de la Pascual 1, se inicia en la Layetania en la década anterior al cambio de era, su floruit se produce con Tiberio (Dressel 3 y 2) y su declive hacia 70-80 d.C. (Berni y Miró 2013: 76). No obstante, se siguió fabricando en el ager de Tarraco ("Dressel 2-4 evolucionada") en la segunda mitad del s. II e inicios del siguiente. Aunque los detalles son poco conocidos, es un indicio de la continuidad de la producción vinaria y tal vez de la exportación durante el siglo II y principios del III y el desplazamiento de su principal foco de producción hacia tierras más meridionales (Járrega y Otiña 2008, Járrega 2013: 408) (fig. 9).

En resumen, considerando la elevada cantidad de alfarerías que la fabricaban y de pecios conocidos, podemos deducir que fue el ánfora de mayor éxito comercial en la Tarraconense. El vino que contenía se consumía abundantemente en las tabernas de Roma, como refleja la conocida cita de Plinio a la que ya me he referido al principio (Berni y Miró 2013: 75-76, Járrega 2018: 176-179).

Cronológicamente, los catorce pecios estudiados abarcan desde los primeros años de la era hasta el año 50 d.C. Esta lista se ha visto incrementada en los últimos años hasta alcanzar los dieciocho pecios, alargando su existencia hasta época flavia (Berni 2015a: figura 4, Carreras 2013: 340-346). En ocho de ellos, los sellos en estas ánforas proceden de dos alfares del Baix Llobregat, Can Pedrerol y Can Tintorer (Corsi-Sciallano y Liou 1985: 165, Berni 2015a: fig. 4), donde se iniciaría el viaje. Otros cuatro de la Layetania Oriental, articulada alrededor de Iluro (Torre Llauder), y otros tres de la Occidental, con centro en Baetulo (Berni 2015a: fig. 4). Estas dos áreas portuarias, el Baix Llobregat y el Maresme, con Iluro y Malgrat de Mar, estarían en el origen del viaje (Carreras y Berni 2002: 366-369), según indica la procedencia de las estampillas halladas en estos pecios (fig. 10).

De los posibles dos o tres pecios del fondeadero de Les Sorres (Dressel 3-2, dolia, lingotes, anclas, junto a algunos restos del casco de las naves) (Nieto y Raurich 1998: 120, Izquierdo 2013: 313-314) sabemos muy poco, pero podrían ser la confirmación del punto

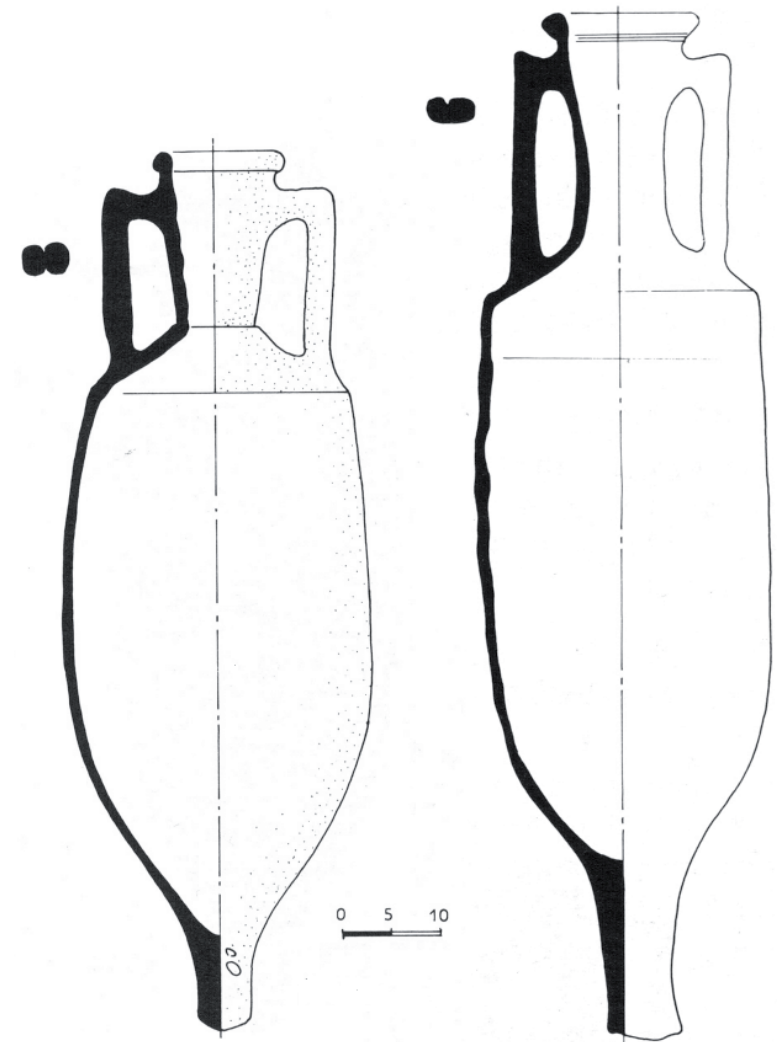

Figura 9. Dressel 3 del pecio Dramont B (izda.) y Dressel 2 del pecio Cavallo 1 (a partir de Corsi-Sciallano y Liou 1985: fig.59: 25.74 y fig. 97.1 respectivamente).

de partida de estos barcos, cuyo cargamento principal eran dolia y las ánforas el secundario, lo cual implica la existencia de unas instalaciones portuarias adecuadas a este fin. Se trata de un viaje directo por alta mar a Roma, su destino principal, vía golfo de León o estrecho de Bonifacio.

Para esta ruta, de nuevo entra en juego Barcino, en una ubicación central privilegiada, tanto para controlar y fiscalizar la salida de los barcos vía delta del Llobregat (entiéndase Les Sorres), en cuyos talleres de la zona se habrían fabricado estas Dressel 3-2, como para la recepción y distribución de las procedentes del Maresme, centralizadas a su vez por Baetulo, que muestra precisamente en época augustea y primera mitad del s. I. d.C. sus años de mayor riqueza demográfica y económica gracias a la producción y comercialización del vino (por ej. Guitart 1976: 243-244). Bien comunicada por mar, pero también por tierra con las zonas productoras de vino (vía Augusta) y vía fluvial (Besòs y Ripoll) con el Vallès, sería la centralizadora y distribuidora del vino de la zona, disponiendo de una red comercial perfectamente 


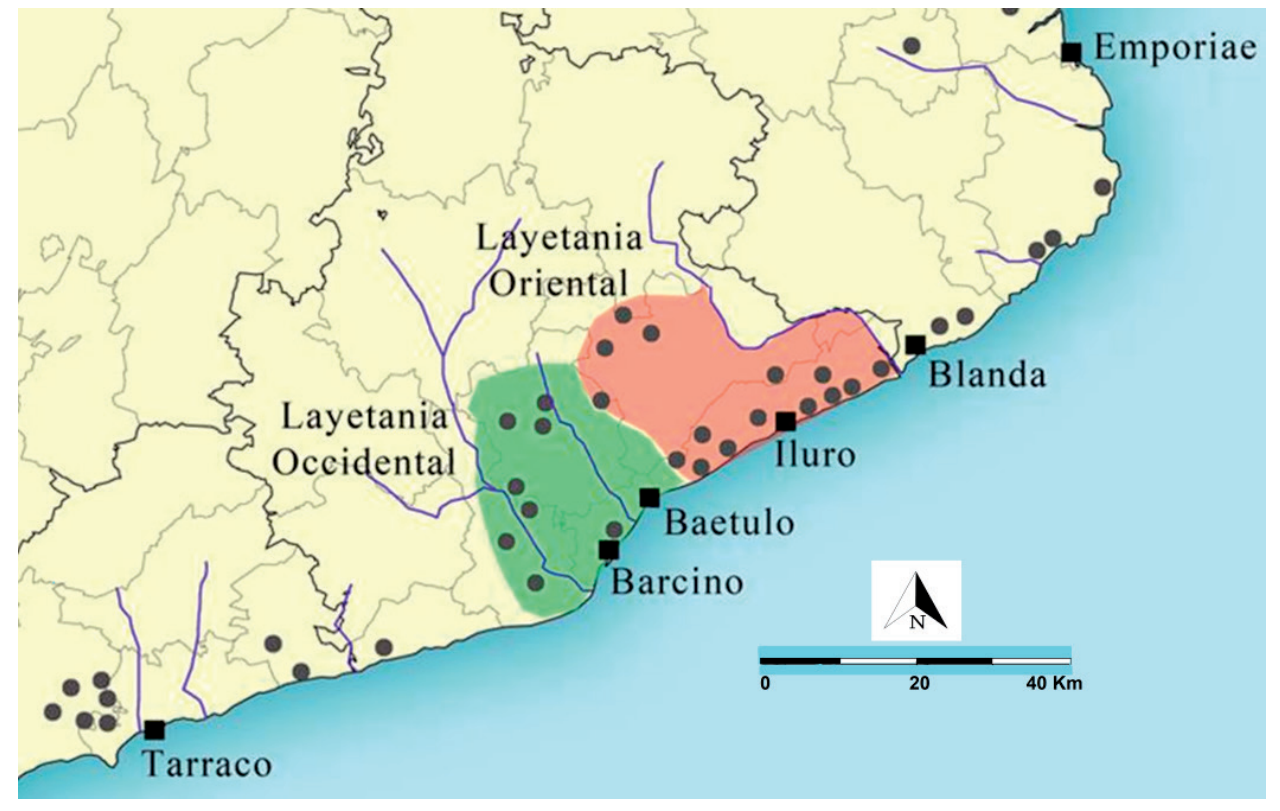

Figura 10. Mapa de la Layetania subdividida en sus dos vertientes, la oriental (El Maresme $\mathrm{y}$ Vallès oriental) $\mathrm{y}$ occidental (Barcelonès, Baix Llobregat y Vallès occidental), con indicación de zonas de centros de producción (a partir de Berni 2015a: fig. 6). organizada para la compra y venta de este producto. De hecho, sería la intermediaria entre productores y exportadores (Comas i Solà 1997: 116-118). Podemos pensar que las Dressel 3-2 producidas en el conjunto de Illa Fradera hasta 20-25 d.C. (Antequera et al. 2010: 174187) formaran también parte en estas primeras décadas de la era de los primeros cargamentos, aunque tal vez ya controlados y fiscalizados por Barcino.

\section{LOS PROTAGONISTAS: INGENUI, LIBERTOS Y ESCLAVOS}

Una serie de investigadores han emprendido el estudio de las propiedades de las gentes más importantes de Barcino, basándose en la toponimia, en la epigrafía de la producción y en la epigrafía monumental, así como de sus redes de producción y distribución y del origen de su riqueza (Olesti 2005, 2009, 2013, Berni et al. 2005, Vila y Monfort 2008, Morera et al. 2010, Olesti y Carreras 2015). La conclusión principal fue que tal vez muchos de los nombres de los fundi que nos han quedado de la documentación altomedieval (derivados de las terminaciones en -anum o-ana) se relacionan con estas propiedades de época imperial. El siguiente paso sería vincular estas propiedades a la producción de vino.

Tenemos, sin embargo, a otros protagonistas. Se trata de los libertos, también presentes en esta toponimia: Nisiano, Nimphianus y Primiliano, cognomina de origen oriental y servil, que además de acceder a su condición de libertos, fueron también propietarios rurales. El origen de su riqueza estaría igualmente ligada al negocio del vino, como se desprende, por ejemplo, del liberto L. Licinius Chresimus (Berni et al. 2005: 175-179). Este personaje es conocido en marcas sobre dolium y se dedicaría a su producción como institor, comprando uva o vino, fermentándolo y envasándolo en dolia con su sello para después transportarlo y ser envasado en ánforas. Entraría así en una cadena de relaciones, entre otros, con el propietario del fundus y de la alfarería donde se producían las ánforas.

Dando por sentada la importancia del sevirato en el Alto Imperio como indicador del dinamismo socioeconómico, J. Pons se preguntaba en 1977, todavía en los inicios de la valoración arqueológica de las ánforas tarraconenses vinarias y sin citarlas, sobre la fuente del enriquecimiento que permitió a estos libertos su ascenso social, sea en la agricultura, el comercio o la industria (Pons 1977: 218). Hoy en día ya conocemos la respuesta y no puede ser casual que la mayor representación de seviri en la epigrafía monumental y honorífica estén en Tarraco y su ager y en Barcino, seguidas a mucha distancia por Dertosa e Iluro. En la Cataluña interior, con un dinamismo social y económico inferior, o en Ampurias, que ya entonces había perdido su papel dinamizador de años anteriores, son realmente escasos (Pons 1977: 218). Es decir, tenemos por un lado a $\mathrm{Ta}$ rraco y su zona de influencia y por otro a la Layetania litoral focalizada en Barcino, sin duda las zonas más 
dinámicas económica y socialmente de la Tarraconense oriental en el Alto Imperio.

Como caso paradigmático, se puede traer a colación a Caius Trocina Synecdemus, liberto de la familia Trocina, radicada en Barcino (Gorostidi 2013). El origen de la cuestión procede de las marcas SYNE y SYN, localizadas abundantemente en el centro productor de Sant Vicenç dels Horts (Baix Llobregat) y en otras áreas del Ager Barcinonensis (Morera et al. 2010), leídas como Synecdemus, un nombre griego desconocido en la epigrafía hispana. A nuestro personaje, que llegó a ser sevir augustal en su vejez, su esposa Valeria Halina le dedicó una inscripción de homenaje para su villa rustica, en la actual localidad de Castelldefels (Baix Llobregat). Dicha inscripción, conservada en un pedestal, había sido fechada en el segundo cuarto o mitad del s. II d.C. Ahora, gracias al reciente estudio de D. Gorostidi, esta datación se ha adelantado a época flavia. Así, en su juventud Synecdemus ejerció como officinator o institor en la gestión de la fabricación de ánforas en la propiedad de los Trocinae, quienes, tras años de buena gestión, le concedieron la libertad y con el tiempo, su promoción al sevirato.

Valgan estos ejemplos como punto de partida para relacionar las propiedades agrarias en manos de las élites barcinonenses y el proceso de fabricación de ánforas a cargo de los libertos, representados sobre todo en los sellos de las ánforas procedentes de los talleres del Baix Llobregat. Sin ánimo de ser exhaustivos, en esta exposición me referiré a los principales personajes presentes en la epigrafía anfórica, según su presencia en los dos tipos anfóricos aquí tratados.

\subsection{Pascual 1}

En un estudio sobre la dinámica del comercio de las ánforas layetanas nos hemos referido a la onomástica en estos envases (Berni y Miró 2013, vid. también Revilla 2007, Járrega 2016a y 2016b para la Pascual 1). Respecto a las marcas sobre Tarraconense 1, más bien escasas por otra parte (Berni y Miró 2013: 65-67), observamos un cambio en los nombres acorde al nuevo orden social del Principado, destacando una jerarquización sobre la base de la condición social del individuo, como resultado del crecimiento del negocio del vino a mayor escala. La fabricación de las ánforas es ahora más compleja, con trabajadores especializados y, con ello, la obtención de una mejor productividad y rendimiento económico. En estos sellos tenemos ya a personajes libres, libertos y esclavos.
Entre los primeros, da la impresión de que se trata de empresarios y propietarios foráneos, quizás inversores con propiedades fundarias en la Tarraconense y con recursos suficientes para producir vino y fabricar sus propias ánforas. Estaríamos así ante verdaderos oportunistas financieros en busca de beneficios a corto plazo. Conocemos, por su nombre estampillado sobre Pascual 1 en forma de tria nomina, al cónsul del año 14 a.C. Cn. Cornelius Lentulus Augur (Gianfrotta 1982); a C. Mussidius Nepos, familia originaria de Sulmo, una de cuyas ramas se trasladó a Roma para su cursus honorum (Barreda 1998); al inversor veronés del orden ecuestre, de época augustea, Publius Baebius Tuticanus (Tremoleda 2005); у a Publius Usulenus Veiento, magistrado narbonés de la misma época (Christol y Plana 1997, Tremoleda 1998) (fig. 11. 7-9). La aristocracia narbonense formaría parte de la producción y comercio de este vino a través de negotiatores de la élite municipal, como el citado Usulenus Veiento y L. Volteilius, los cuales eran propietarios de terrenos con talleres en la Layetania y distribuían el vino desde Narbona hacia el mercado del oeste galo (Laubenheimer 2015: 189).

Acerca del propietario de la tierra donde se implantaban estas figlinae, habría que diferenciar según fueran propietarios individuales o del ager publicus, en cuyo caso, si el territorio del Baix Llobregat formaba parte del de Barcino, o al menos estaba bajo su influencia, esta sería la protagonista de la gestión y desarrollo de estos centros y en su favor está el hecho de que estos talleres aparezcan simultáneamente con la fundación de la colonia (Járrega 2018: 191). Otros personajes libres se registran con duo nomina (fig. 11.1-6) y en forma abreviada y tria nomina con las iniciales (fig. 11.10-13).

Por su parte, los libertos, adscritos al proceso de producción de las ánforas, figuran con nomen y cognomen, como los del clan de los Iulii, bien conocidos en los hornos del Baix Llobregat y de Calella (El Maresme) (Berni y Miró 2013: 69-70): Iulius Anicetus, $C$. Iulius Anteros, Iulius Theophilus, Iulius Ruf(us), Iulius Papus, cuya aparición en el sellado de las ánforas layetanas encaja con el horizonte fundacional de la ciudad durante el tercer viaje de Augusto a Hispania (16-13 a.C.). Esta repentina aparición de libertos en un corto espacio de tiempo (Anteros, Papus, Theophilus, Rufus?) y el modo hasta entonces desconocido de formular los textos de los sellos, parecen responder a una nueva realidad económica, mediante un sistema de explotación mucho más complejo y sofisticado.

En concreto, la promoción social y la obtención de la ciudadanía de los C. Iulii en la Hispania Citerior 


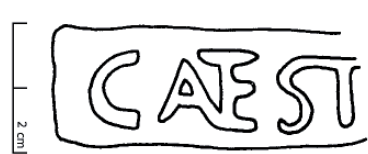

1

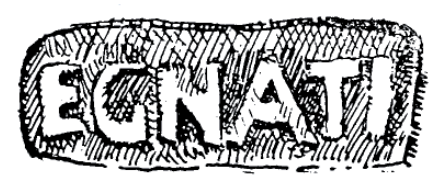

5

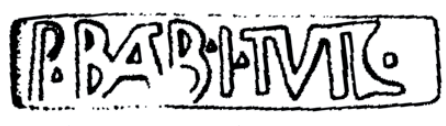

7

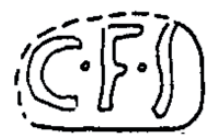

10

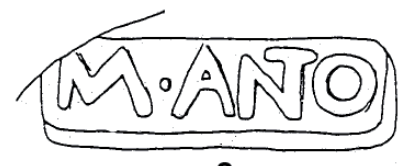

2

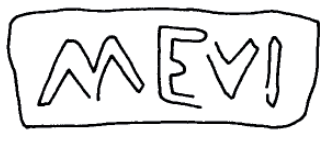

6

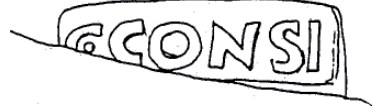

3

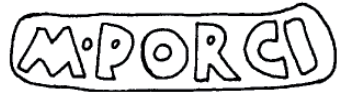

4

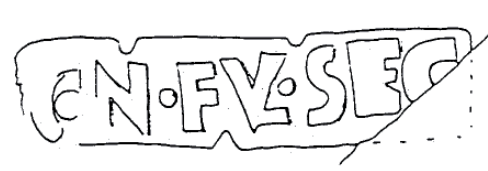

8

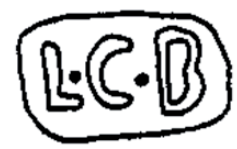

12

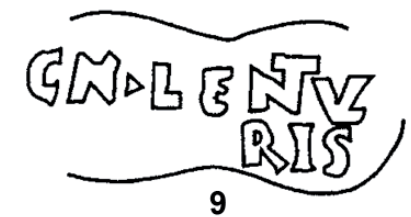

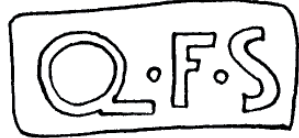

11
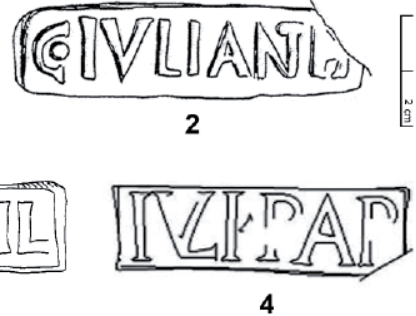

4

Figura 12. Formas de representación de los Iulii sobre Pascual 1 de la Layetania (Berni y Miró 2013: fig. 5).

(Tarraco, Barcino y Segobriga son las ciudades mejor representadas a este respecto por la epigrafía) han estado vinculadas a las políticas de César y Augusto en el proceso de conquista y romanización, a través de promociones jurídicas y deductiones de colonos. En estas civitates, su origen es diverso: veteranos licenciados, ciudadanos romanos instalados en el momento de la fundación o en una segunda deductio y sus descendientes, o incluso antiguos indígenas incorporados como colonos o ciudadanos de pleno derecho (Ortiz de Urbina 2014: 112; inventario de los Iulii en ánfora, en particular de los Theophili, en: Mauné (2012); lista de los C. Iulii de Barcino: Armani 2014: anexo $\mathrm{n}^{\circ} 9$ a 17) (fig. 12).

El sello de Iulius Theophilus nos da pie a considerar el papel de la gens Iulia, tan bien representada en la epigrafía de Barcino, con más de 40 miembros, lo que lleva a creer que una parte de los primeros pobladores serían indígenas que habían recibido la ciudadanía con Augusto (Járrega 2016a: 172). Un C. Iulius Seneca Licinianus fue promocionado al orden ecuestre, desempeñando varios cargos (tribunados militares, edilidad, duunvirato) (Armani 2014: anexo $\mathrm{n}^{\circ}$ 13, Ortiz de Urbina 2014: 103-104). Por otro lado, conocemos a un $C$. Iulius $A(\ldots)$ en una exedra honorífica hallada en Montjuic junto a un L. Licinius, fechada en época de la fundación. Ambos parecen ser magistrados, lo cual indicaría la presencia de clientes de Augusto en la colonia ya desde sus orígenes (IRC IV 62), a la vez que su vinculación con los Licinii.

Finalmente, contamos con una serie de nombres únicos que por defecto atribuimos a esclavos y que son un antecedente de los cognomina de condición servil de las Dressel 3-2 (Berni y Miró 2013: 69-70).

\subsection{Dressel 3-2}

Hemos visto anteriormente que se trata de una producción y de un mercado totalmente diferente al de la 


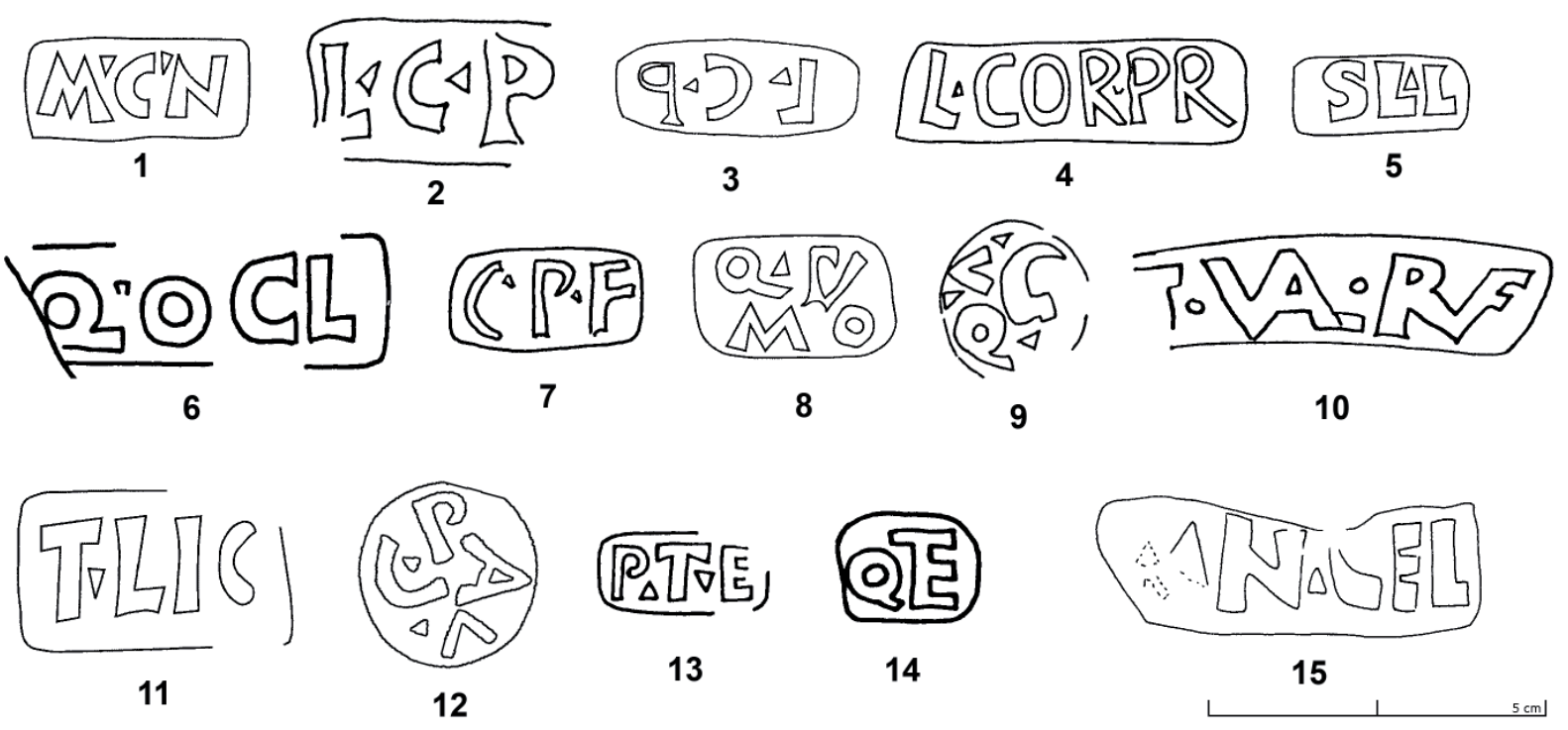

Figura 13. Personajes libres sobre Dressel 3-2 (Berni y Miró 2013: fig. 12).

Pascual 1, lo cual tiene su reflejo en la epigrafía anfórica y en la onomástica de los personajes (Berni y Miró 2013: 75-81). Aparecen aquí los personajes libres en forma de tria nomina $(\mathrm{L} \cdot \mathrm{L} \cdot \mathrm{C}, \mathrm{M} \cdot \mathrm{C} \cdot \mathrm{N}, \mathrm{L} \cdot \mathrm{C} \cdot \mathrm{P}$, $\mathrm{L} \cdot \mathrm{COR} \cdot \mathrm{PR}, \mathrm{M} \cdot \mathrm{C} \cdot \mathrm{N}, \mathrm{M} \cdot \mathrm{S} \cdot \mathrm{PVP}, \mathrm{T} \cdot \mathrm{VAL} \cdot \mathrm{RVF}$, etc.). Menos representativa es la fórmula arcaica de praenomen y nomen (T.LIC, L·VOLTEIL, etc.) y unos pocos en forma de duo nomina (IVLI·THEOPHIL, MIN·CEL) (fig. 13). Sin embargo, la preponderancia de los nombres simples, atribuidos a los esclavos, es absoluta, siendo mayoritarios los que proceden de los alfares del Baix Llobregat, con una cincuentena de nombres abreviados, de dos a cuatro letras cuya lectura podemos completar: Aemulus, Albanus, Calamus, Celsus, Faventinus, Helenus, Optatus, Primulus, Privatus, Synecdemus, Theophilus, etc., a veces formando parejas, con improntas muy vistosas, grandes y con nuevos rasgos formales.

La presencia de estos sellos se atribuye al proceso de fabricación de las ánforas. Reflejarían situaciones de control y contabilidad del mismo a cargo de los esclavos de estas alfarerías. Lo que es más, en ocasiones un mismo nombre aparece en sellos de diferente matriz, p.ej. Albanus en ocho variantes con 38 sellos, la mayoría en la factoría de Can Pedrerol y a veces junto a otro sello, lo que indicaría su movilidad por el consorcio industrial del Baix Llobregat, asociado a otro colega (Revilla 2007: 1189-1192; Berni y Carreras 2013: nº 8, Berni y Miró 2013: 78-80 y fig. 15), formando parte de asociaciones (¿cooperativas?) de alfareros (fig. 14). Esta movilidad se documenta también entre diferentes comarcas, como es el caso de los alfares del Mujal (Calella de Mar) y los del Baix Llobregat, a más de $50 \mathrm{~km}$ de distancia (Berni y Miró 2013: 80-81).

Este hecho, único en la Layetania, sin duda debe obedecer a un plan estratégico planificado desde la Barcino recién fundada, creado para su crecimiento y beneficio. Durante los últimos años de Augusto y la primera mitad del reinado de Tiberio, el Baix Llobregat se convierte en la principal zona de fabricación y envasado de ánforas vinarias de la Tarraconense. Los pecios con Dressel 3 son buena prueba de ello, pues de los dieciocho con cargamento de estas ánforas, recopilados por P. Berni (2015a: fig.4), ocho tienen un origen en el Baix Llobregat y otros siete se reparten entre la Layetania occidental y oriental, con lo cual el protagonismo de Barcino, directa o indirectamente, es ya notable en sus inicios.

Asimismo, esta abundancia de cognomina de origen servil refleja el dinamismo del crecimiento social de Barcino, mostrando su capacidad integradora al ofrecer a estos colectivos dependientes, con su vinculación a actividades industriales y comerciales, la posibilidad de una promoción social y económica (p. ej. Vila i Monfort 2008: 101, Gorostidi 2013: 289, Berni y Miró 2013: 80). En mucha menor cantidad aparecen nomina. Al principio de este apartado se han mencionado algunos ejemplos y conocemos un catálogo de 36 sellos sobre Dressel 3-2, entre ingenui y libertos (Járrega 2018: 


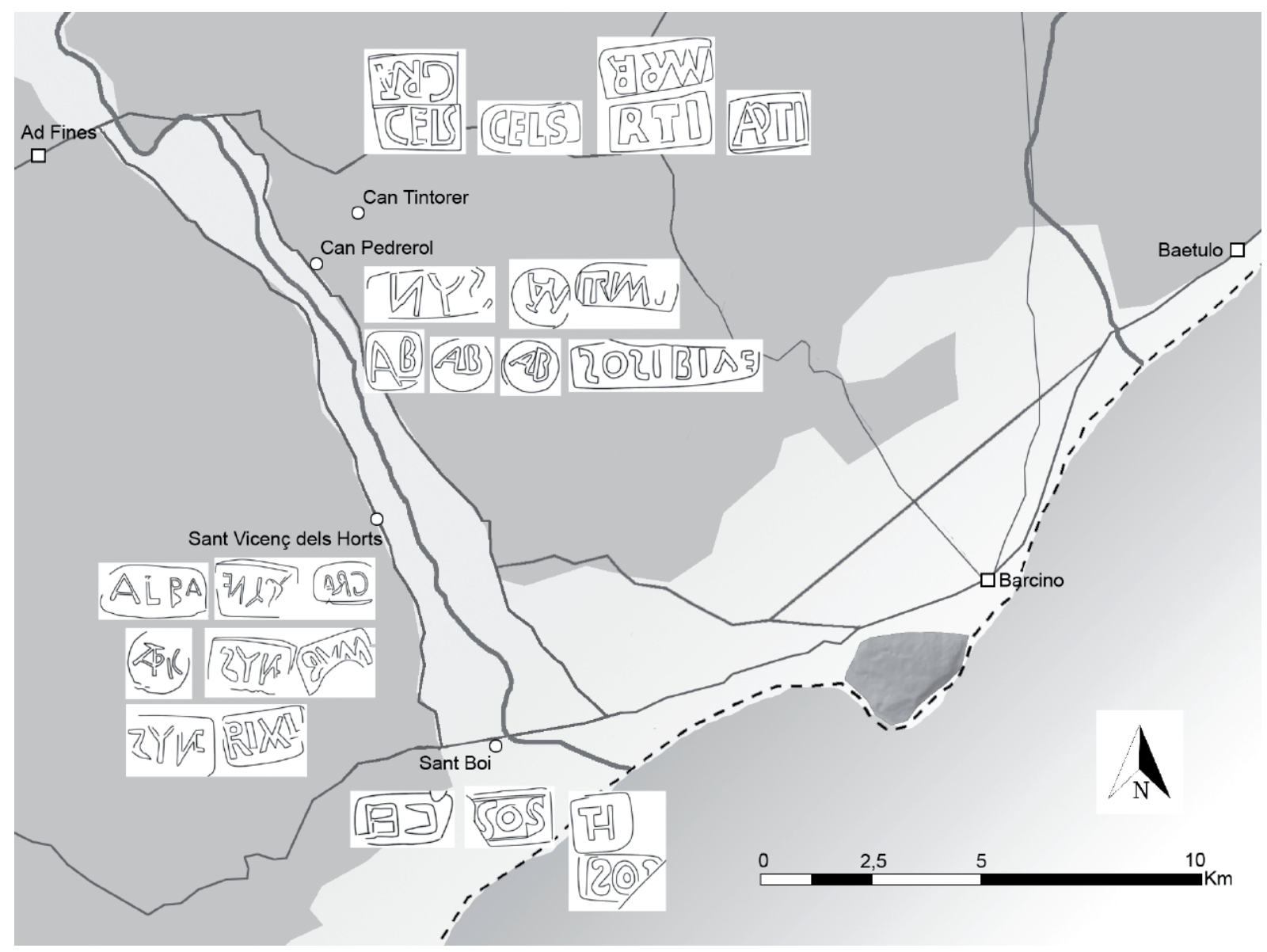

Figura 14. Movilidad territorial de los personajes representados en sellos del Baix Llobregat con distintas matrices selladoras (Berni y Miró 2013: fig. 15).

179-194). Se trata de nombres genéricos, conocidos entre las élites especialmente de Barcino, como los Cornelii, Licinii, Valerii y quizás Flavii y Paulii, de los que hemos visto, a partir de la toponimia, que podemos atribuirles propiedades en el territorio de la ciudad según la documentación medieval (Járrega 2018: 195). Así, tenemos respectivamente los topónimos/fundi Corneliano (Cornellà, Baix Llobregat), Licinianum (Lliçà d'Amunt o d'Avall, Vallès oriental), Semproniana (cerca de Granollers, Vallès oriental), Valleriana (Vallirana, Baix Llobregat) y Paulinianum (Polinyà, Vallès occidental) (Olesti y Carreras 2013: 21-22, 24-25) (fig. 15).

De hecho, se trata de la continuidad cronológica de la hipótesis de J. Pons, centrada en la documentación escrita de la época, esto es, los itineraria romana entre Gades y Roma, a su paso entre Tarraco y el Pirineo (Pons 1985: 130-132). Siguiendo a este autor, por la vía Augusta discurren más de una docena de mansiones, algunas con un nombre personal itálico con el sufijo -ana y que corresponderían a propiedades agrarias conocidas a partir del nombre de su primer propietario: Palfuriana, Antistiana, Semproniana, Cinniana y Deciana, relacionando el origen de la producción vinícola de la zona con los asentamientos de población itálica desde el periodo republicano y augusteo. Es más sorprendente que en este corto tramo aparezcan tantas mansiones, un tercio del total, cuyo nombre procede de la onomástica itálica, en vez de un núcleo de población o de postas y que, al figurar cuatro de ellas en los vasos de Vicarello, pueden ser datadas desde el principio del Principado de Augusto (fig. 16).

Pasando ya a Barcino, la lista de estos personajes presentes en la epigrafía honorífica y monumental de la ciudad es extensa (p.ej.: Olesti 2005: 165-172, con 17 nombres). Aquí solo se mencionará a los que se les pueda relacionar con la posesión de un fundus en la Layetania y con los hallazgos de sellos anfóricos sobre Dressel 3-2 layetanas. 


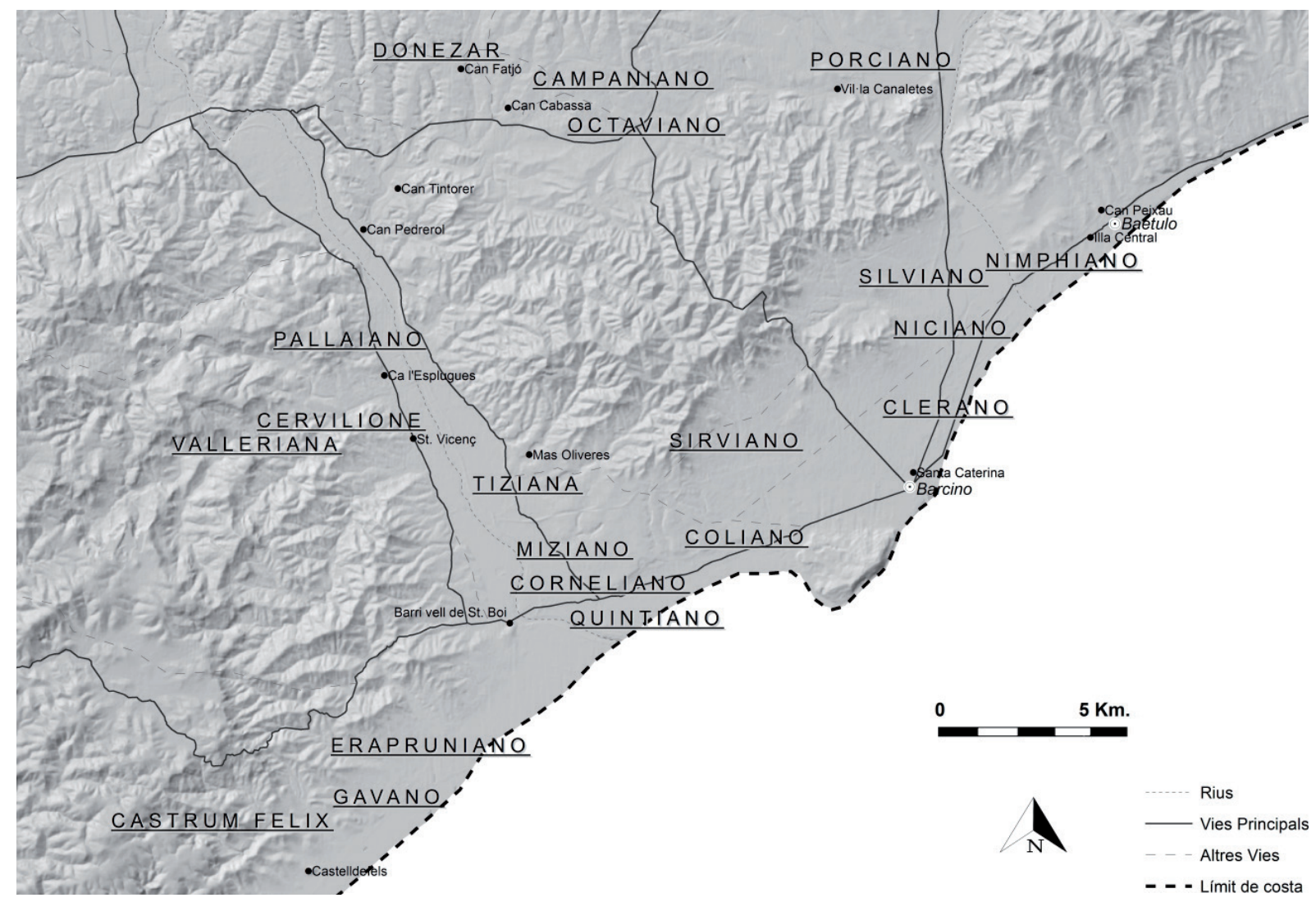

Figura 15. Topónimos altomedievales de fundi derivados de cognomina (a partir de Olesti y Carreras 2013: fig. 3).

\subsubsection{La gens Cornelia}

Es una de las más conocidas de Barcino, con casi 30 inscripciones (IRC IV 403, Berni et al. 1998, Olesti y Carreras 2013: 171-172, Járrega 2018: 180-181). De la documentación procedente de alfares, hallazgos aislados o en contexto y pecios, podemos mencionar a dos personajes:

- Lucius Cornelius Pro(culus?): representado por la marca $\mathrm{L} \cdot \mathrm{COR} \cdot \mathrm{PR}(-)$, muy posiblemente $\mathrm{L} \cdot \mathrm{C} \cdot \mathrm{P}$, del alfar productor de Pascual 1 y Dressel 3-2 de Can Cabot (Santa Eulàlia de Ronçana, Vallès Oriental) (Pascual 1991: no 119) (fig. 13.2-4) y datado en la primera mitad del s. I d.C. Los sellos, por la pasta cerámica, se atribuyen al Vallès Oriental, es decir, a la zona de Lauro y por lo tanto del vino lauronense (Berni et al. 1998: 114-115 y 117-118). Más exactamente, una datación a mediados de este siglo vendría confirmada por el pivote estampillado $\mathrm{L} \cdot \mathrm{C} \cdot \mathrm{COR}$ PR de Can Cabot, claramente una Dressel 2 tardía (Pascual 1977: fig. 12, 4 y 10) y por lo tanto datable desde 50 d.C., al inicio de los Flavios
(Berni 2015a: fig. 8). Por otra parte, su presencia en Iluro, en una amortización datable en época flavia (Berni et al. 1998: 114 y fig. p. 122), nos confirmaría esta datación y además, si fuera generalizable, la recepción en la ciudad de producciones del Vallès para ser embarcadas.

- Quintus Cornelius Ner(-): la lectura de este sello, de procedencia no layetana (tal vez de Tarraco o zonas más meridionales), se caracteriza por la peculiar forma de sus estampillas, que son bilineales y están en la parte baja del cuello del ánfora, lo que es poco habitual en las Dressel 3-2 layetanas, pues la mayoría se sitúan en el pivote. Aparece asociado a dos nombres serviles, Eros y Fuscus, con toda probabilidad los esclavos encargados de la alfarería. Se conocen cuatro de estas estampillas, dos para cada uno de ellos (Berni et al. 1998: 123). Es de nuestro interés Fuscus, al haberse encontrado asociado con $Q$. Corn(elius) en un mismo sello situado en el cuello de una Dressel 3-2 junto a un elenco de estampillas poco conocidas (EVP, HAM, FLAVI) del pecio de Marina di Fiori. Se trata de una nave con 


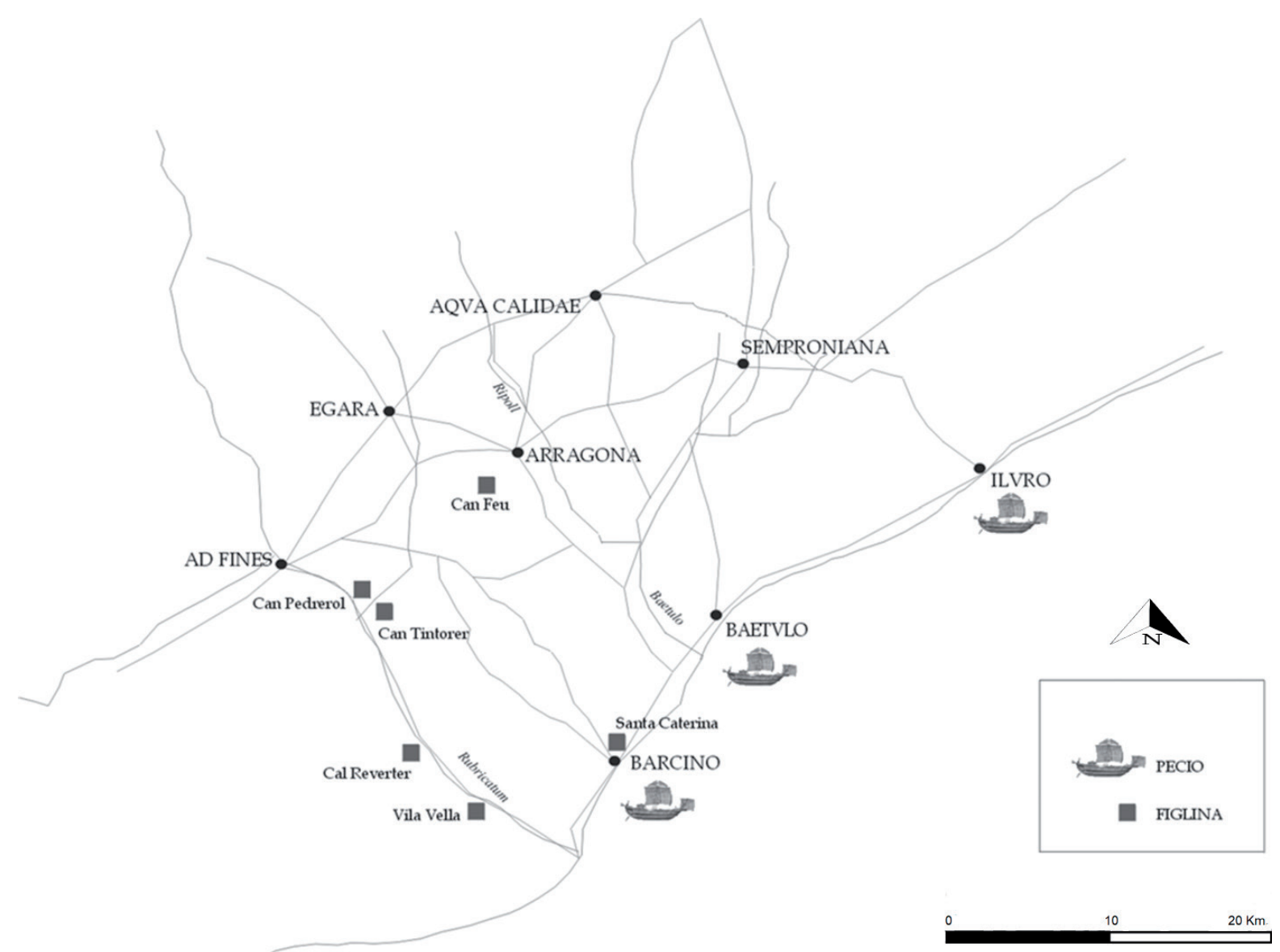

Figura 16. Barcino y sus alrededores, con las mansiones y centros de producción anfórica cercanos y lugares de embarque (a partir de Vila y Monfort 2008: fig. 1).

cargamento mayoritario de Dressel 3-2 tarraconenses, hundida en Córcega en época flavia (Bernard 1996), muy probablemente del ager de Tarraco.

Más recientemente, se ha propuesto que la marca EVP pudiera ser una variante más moderna de EVPRA obrada en Mas de Gomandí (Baix Camp, Tarragona), de donde procede la marca, rectificando así una primera lectura (Berni 2010: 169-170). Tenemos pues, por una parte, la confirmación de la época flavia para la datación de ambos personajes, cuyas ánforas se marcaban en Tarragona, y además la existencia de un navío con cargamento heterogéneo (lo que no es habitual) de ánforas Dressel 2 del ager de Tarraco, incorporándose a la ya citada lista de dieciocho pecios de Dressel 3-2. Ninguno de los dos Cornelii parece tener vinculación directa con Barcino, aunque sí con el negocio del vino. Así parece demostrarlo el sello sobre dolium (-) COR·PR(---), procedente de las estructuras productivas de vino de la villa de Can Pedrerol (Baix Llobregat) y que indicarían la implicación de un miembro de esta familia en la fabricación de estos contenedores para su almacenamiento (Berni y Carreras 2013: $280 \mathrm{n}^{\circ} 156$ ). El primero parece más vinculado al Vallès oriental y tal vez al vino de Lauro. El segundo, sin embargo, sería la muestra de la expansión de la familia en otras áreas de la Tarraconense, ya dentro del circuito del comercio de las Dressel 3-2. Tal vez la Layetania, ya con los Flavios, fue perdiendo su importancia comercial en beneficio de Tarraco, a juzgar por el pecio de Marina de Fiori, y su floruit habría pasado ya.

\subsubsection{La gens Licinia}

El gentilicio Licinius (Berni et al. 2005, Olesti y Carreras 2013: 167-168, Járrega 2018: 183-184) es uno de los más comunes en Hispania, especialmente en la 
Tarraconense y en Barcino y cercanías, con un total de 305 inscripciones según J. Abascal (1994: 168), donde ya hay miembros en época augustea, uno de cuyos magistrados fue un Lucius Licinius (Rodà 2014: 22). Cuando se incluye el praenomen, en algo más de la mitad de ellas, se trata en primer lugar de Lucius en número de menciones. A partir del momento en el que las provincias hispanas se incorporan al imperio, magistrados de esta gens ejercen sus funciones en las mismas. A finales del s. I a.C. los hallazgos del gentilicio aumentan y con Augusto, en el 14 a.C., un Marcus Licinius Crassus Frugi, del que se conoce una posible inscripción en Tarraco, es legatus propraetore Hispaniae Citerioris (RIT 131).

En época julio-claudia parecen disminuir en la epigrafía monumental tarraconense, pero a finales del s. I d.C. varias inscripciones los relacionan con posibles propiedades en Baetulo y algo más tarde aparece la figura de L. Licinius Sura (Rodà 2014), sobradamente conocida en la epigrafía monumental y honorífica de Barcino, con 22 pedestales (IRC IV 83-104), al lado de su liberto y accensus L.Licinius Secundus (Rodà 1970). Acerca de su riqueza y relaciones, J. Pons indica su posible nexo con la familia senatorial de los Palfurii y, en consecuencia, con el praedium de Palfuriana, cercano a Tarraco, hasta el punto de que Licinius Sura podría haberlo heredado a raíz de la ejecución de Palfurius Sura. Incluso podría haber pasado esta propiedad a su liberto Licinius Secundus a su fallecimiento (Pons 1985: 135-136). Vemos así lo que es una constante, las estrechas relaciones familiares, sociales y económicas entre estas familias de la élite y al mismo tiempo su movilidad geográfica, de modo que al estar tan íntimamente conectadas, deban verse conjuntamente.

A principios del s. II d.C. se aprecia una penetración al interior layetano y también en el Maresme del nombre, con un Licinius Faventinus en Iluro, tal vez la expresión de la continuidad de la familia en Barcino a pesar de residir fuera de ella. A lo largo de la segunda mitad de este mismo siglo reaparecen en Tarraco casi en exclusiva y en el s. III conocemos solo uno de esta capital. En conjunto, predomina el praenomen Lucius y es en Tarraco, y sobre todo en el área de Barcino donde mejor se documenta el gentilicio en la epigrafía monumental (Berni et al. 2005: 168-169).

Pasando ya a los sellos en ánforas que los relacionen, hemos de admitir que no son muchos y no excesivamente claros. Han sido recopilados globalmente (Berni et al:: 172-175) o divididos por tipo de ánfora (Járrega: 2016b y 2018): uno de ellos (LICIN) sobre
Pascual 1 en el pecio Cap Béar 3, el más antiguo (5030 a.C.). Los que con mayor probabilidad, siempre en el terreno de las hipótesis, sobre Dressel 3-2, pueden pertenecer a la familia son los siguientes: TLIC (fig. 13.11) y N $\cdot \mathrm{L} \cdot \mathrm{L}$ hallados en el pecio de Chrétienne H (15-20 d.C.), que se leen T. Lic(inius) y N. L(icinius) L(icinianus?) respectivamente ) y LLL Lucius Licinius $L(\ldots)$ del pecio de la Giraglia, en Córcega (c 20 d.C.). Sobre pivote de tipo indeterminado: NLIC, localizado en Badalona y LLC, Lucius Licinius C(...) de Ampurias y Barcelona. Finalmente, del alfar de Sant Miquel dels Martres (Caldes de Montbui, Vallès Oriental, zona de Lauro) donde se producían Pascual 1 y Dressel 3-2, conocemos LL·Q y SLL (fig. 13.5), leídas Lucius Licinius $Q($...) y Sextus o Secundus Licinius $L(. .$.$) (Berni y$ Miró, en prensa).

Finalmente, cabe citar la marca C.LIC.ADIN sobre dolium de la cella vinaria de Can Pedrerol (Castellbisbal, Baix Llobregat) y que se une a la de la gens Cornelia ya citada. Sería de nuevo la expresión de la vinculación de la familia a la fabricación de estos contenedores relacionados con el vino (Berni y Carreras 2013: $\left.281 \mathrm{n}^{\mathrm{o}} 158 \mathrm{a}\right)$.

Los alfares nos proporcionan más información, pues la marca SLL procede de Sant Miquel dels Martres y de Can Cabot (Santa Eulàlia de Ronçana, en las proximidades del anterior, Vallès oriental). Por otra parte, acudiendo a cartularios medievales, ha sido posible localizar con precisión la ubicación del topónimo Liciniano en el Vallès oriental, cerca del Besòs, en la localidad de Lliçà, cerca de Granollers (Berni et al. 2005: 180; Olesti 2009: 147-148). Se trata de un territorio de notable extensión, bien comunicado y solo aparece mencionado en este lugar. Lo que es más, se trataría de una de las propiedades de prestigio bajo la administración de Licinio Segundo, hombre de confianza y accensus de Licinio Sura, dedicada a la explotación vinícola antes de la época flavia (Mayer 1996: 24).

De confirmarse la lectura de la marca SLL y atribuibles las demás a la misma zona, tendríamos una importante propiedad en el territorio de Lauro en manos de los Licinii y unos centros productores en los que marcaban sus ánforas en la misma comarca, para ser transportadas con toda probabilidad a Baetulo e Iluro y desde allí embarcadas.

En relación a un fundus Licinianus, Marcial (1.49.19-20) nos habla de la vida retirada de Caius Licinius Mucianus, antes quizás senador de la Tarraconense con Nerón y Vespasiano, gestionando los recursos de sus propiedades, con toda probabilidad, 
tierras dedicadas a la producción de vino. Marcial comenta que este personaje alababa a Licinius Sura, con posibles lazos de amicitia, más allá de la pura anécdota (Berni et al. 2005: 169-170). Por otra parte, el topónimo Liciniano solo aparece aquí, por lo que probablemente sería una explotación muy importante, dando por sentado que en época romana la continuidad de los nombres se ha conservado en el del primer propietario (Berni et al. 2005: 180-181).

En conclusión, parece demostrado que existieron bastantes miembros de la gens dedicados a la explotación del vino layetano en la primera mitad del s. I d.C. No solo como propietarios de tierras para el cultivo de la vid y de centros de fabricación de ánforas, sino también como institores, como parece ser el caso de nuestro Chresimus, probablemente un liberto con cognomen de origen griego que se encargaba de un primer nivel de gestión en los centros productores. Actuaría también como intermediario entre propietarios de fincas y productores de vino, o incluso tal vez fuera el propietario del vino contenido en dolia. Rizando el rizo a nivel puramente hipotético, ¿podría tratarse del LLC del sello de Ampurias y de Barcelona y haber llegado a ser productor de ánforas? ¿O fue tal vez un liberto del Lucius Licinius Sura de época augustea que figura en una inscripción del arco de Berà, como se pregunta I. Rodà? (2014: 22).

Existió pues en la zona cercana a Barcino y sus municipios adyacentes una alta densidad de propiedades y alfares vinculados desde época augustea a los intereses de los Licinii, los cuales ya formaban parte de las magistraturas de la colonia, como consecuencia de los privilegios derivados de la deductio. En ella residirían sus miembros más importantes y de aquí procedería su riqueza patrimonial, articulada en la producción vinícola como propietarios de fundi al principio, pero después como participantes en la elaboración del vino y en la gestión de los alfares. Paralelamente, se desarrollan los actos evergéticos de la familia en la colonia y en el s. II d.C, desaparecido ya el fenómeno económico que le dio origen, sus actividades se diversifican, posibilitando el surgimiento de personajes como L. Licinius Sura y su accensus Secundus (Berni et al. 2005: 184-185).

No se nos puede escapar la vinculación de esta familia con la gens Minicia. Como botón de muestra, Quinto Licinio Silvano Graniano, el prefecto de la ora maritima y patrono de Baetulo, ya citado anteriormente, fue cónsul en el 106 d.C. con Lucius Minicius Natalis y junto a otros lazos familiares bien conocidos, vemos así la estrecha relación entre ambas poderosas familias, la primera seguramente originaria de Tarraco pero trasladada a Baetulo y la segunda, originaria de Barcino (Rodà 2010: 186). Parece estar fuera de toda duda que los Minicii Natales, o al menos alguno de los Minicii, poseyeron tierras, tal vez en el fundus Minicianus, que puede situarse por Sant Joan Despí (Baix Llobregat) (Mayer 1996: 24-25; Olesti 2005: 181; Olesti y Carreras 2013: 165).

Sin embargo, los Minicii no están tan bien representados en la epigrafía anfórica como los Licinii. Pero precisamente de Sant Joan Despí procede [MIN] CEL [Min(ici) Cel()]. Aunque falta la primera parte, gracias a otra inscripción, MIN · CEL con la grafía y punzón idénticos, hallada cerca de Vic (antigua Ausa) (fig. 13.15) sobre una Dressel 3-2 con una datación de contexto de c 30-40 d.C., ha sido posible restituir esta lectura (Berni y Carreras 2013: 210 y fig. $\left.n^{\circ} 78\right)$. Sin embargo, se trataría de una Dressel 3 tardoaugustea hallada en un contexto más tardío (información personal de P. Berni). Si la primera procediera de los alfares del Baix Llobregat, por su proximidad, podríamos formular la relación de los Minicii con la producción y comercio de vino layetano ya desde época augustea.

\subsubsection{La gens Pedania}

Los Pedanii están bien documentados en Barcino con una treintena de inscripciones (IRC IV 405, Rodà 1975 y 2010: 182-185). Del complejo industrial vitivinícola de Veral de Vallmorà (Teià, El Maresme) procede un signaculum de plomo con la leyenda EPICTET(us) L(uci) $\mathrm{P}$ (edani) CLEMENTIS, muy probablemente destinado a marcar dolia. Fue identificado como Epicteto, esclavo de Lucius Pedanius Clemens (Rodà et al. 2005, Martín et al. 2007). En una inscripción (IRC IV 106), datable posiblemente bajo Trajano, una Acilia Arethusa le dedica la lápida a su marido Lucius Pedanius Epictetus, sevir augustal y en otras dos (IRC IV 107 y 108), Lucius Pedanius Clemens se las dedica a otros libertos. La primera sería del primer cuarto o mediados del s. II d.C. Probablemente este Pedanius Clemens fue el patrón de Epicteto, aunque es difícil asegurarlo. De hecho, son los continuadores de una extensa saga iniciada en la segunda mitad del s. I d.C.

De lo que no parece haber duda es de que este linaje de los Pedanii explotaba los recursos vinícolas de esta zona del Maresme, en una de las raras ocasiones en que conocemos el nombre del liberto encargado de ello en nombre de su amo, Lucio Pedanio Clemente. Una vez conseguida la libertad y su promoción como parte 
de la familia, se casó con otra liberta de la gens Acilia (Rodà et al. 2005: 55). Esta industria estuvo en funcionamiento mucho tiempo, desde el s. I a.C. al VII d.C. pero aquí nos interesa la fase 2 , con una primera etapa a pleno rendimiento, entre 40-70 d.C. y la segunda (c 75150 d.C.), coincidiendo con la época de nuestros personajes (Martín et al. 2007: 202).

\subsubsection{La gens Valeria}

La gens Valeria (Olesti y Carreras 2013: 170-172, Járrega 2018: 185-186), está presente 26 veces en la epigrafía de Barcino (IRC IV 405) y son propietarios de dos fundi, uno en el Vallès Occidental, Valrano, y otro en Vallirana (Baix Llobregat), Valleriana, ya en el interior del curso del río y algo apartado de él. Los estudiosos de las marcas del Baix Llobregat proponen asociar (Q?)VAS, QVA, QVALE y VALE en pivote al nomen Valerius, si bien con reservas, dada a veces su difícil lectura, y cuyo lugar de producción sería Sant Boi de Llobregat (Berni y Carreras 2013: n 120), aunque R. Járrega (2018: 185) descarta unificar las dos primeras con las demás. La lectura más probable es pues Quintus Vale(rius) y de admitir las dos primeras, se trataría de un tria nomina: $Q$. Va(lerius) $S($...). La más numerosa es QVA, con 16 ejemplares, en el pecio de la Chrétienne H (15-20 d.C.), donde está asociada a otras (Corsi-Sciallano y Liou 1985: 84 y no 47) y también estaría QVALE, aunque con dudas. Del mismo taller de Sant Boi procede el sello FAV (Faventinus?) (Berni y Carreras 2013: $\mathrm{n}^{\circ}$ 56), documentado también en la Chrétienne H (Corsi-Sciallano y Liou 1985: 82 y n $^{\circ}$ 26). Finalmente, conocemos a un $Q$. Valerius Faventinus en un bloque de gres de Montjuic (IRC IV 222).

\section{LOS CONSUMIDORES}

La etapa final de este comercio nos lleva a los receptores del vino contenido en estas ánforas. El vino tarraconense era muy apreciado por las élites del Oeste de la Galia pues se trataba de un bien de prestigio (Tchernia 1987: 331), hasta el punto de que además de consumirlo, lo ofrecían en las tumbas aristocráticas. Las ánforas Pascual 1 recibían un trato especial en los pozos funerarios de la zona (Laubenheimer 2015: 189-190), así como en la tumba $\mathrm{B}$ del conjunto luxemburgués de Goeblingen-Nospelt (c 20 a.C.) (Martin-Kilcher et al. 2009, González Cesteros 2015: 209). Fue apreciado este caldo hasta el punto de ser esta ánfora imitada en la
Narbonense para comercializar el vino local desde los inicios del s. I d.C.. Llegó a su punto álgido en época flavia, lo que provocó la crisis de estas exportaciones layetanas, al cubrir la producción gala las necesidades del país (p.ej.: Laubenheimer 1985 y 2015: 190). Los caudillos galos eran muy aficionados a su consumo, como lo fueron en años anteriores al itálico envasado en las ánforas Dressel 1, al que sustituyó, cuando ya no compensaban los transportes marítimos de estas ánforas itálicas a gran escala y a la espera de que la producción gala lo supliera (Tchernia 1987: 331). Y ello a pesar de que el vino de las Pascual 1 no fuera de muy buena calidad, al menos es lo que parecen indicarlo los ejemplares recuperados en los pecios de Els Ullastres y Cap del Vol, pues los opérculos para cerrarlos presentaban un orificio y por lo tanto no habían acabado el proceso de fermentación, tratándose de vinos jóvenes (Nieto y Raurich 1998: 124).

Diferentes son los consumidores del vino de las Dressel 3-2. Los pecios indican que su destino principal era Roma, donde tenemos que ver a la clientela principal. Además, estas naves llevaban también vino envasado en dolia, lo que nos lleva a plantear la cuestión de si ambos envases llevaban el mismo tipo de vino, como por ejemplo, proponen las autoras del estudio del pecio de la Giraglia (Marlier y Sciallano 2008: 151), o por el contrario el de los dolia sería de una calidad inferior, destinado a un consumo inmediato (p.ej.: Gianfrotta y Hesnard 1987: 297, Dell'Amico y Pallarés 2011: 73). Posiblemente la segunda opción sea la correcta, pues de otro modo sería difícil explicar, p.ej., que la docena larga de Dressel 3-2 (la mayoría son Dressel 2) conocidas, estén escritas con tituli picti que hacen referencia a un vino de calidad como el lauronense, en ocasiones vetus de cuatro años, halladas en Roma, Ostia y Pompeya (cinco ejemplares) y Cartago (dos ejemplares) (Berni 2017: fig. 9). Lo cual no implica, lógicamente, que todas las Dressel 3-2 contuvieran vino lauronense. De hecho no se ha encontrado ningún titulus con esta indicación en los citados pecios, si bien estos no son frecuentes en yacimientos submarinos, dadas las dificultades para su conservación. Por otra parte, hemos propuesto recientemente la asociación Dressel 3 -vino abundante de calidad mediocre y Dressel 2 - vino apreciado, de calidad superior, tipo lauronense (Berni y Miró, en prensa), cuestión en la que habrá que profundizar para corregirla o confirmarla. Lo que parece claro es que se trata de la «faex laletana» que Marcial (1.26.9-10) aconseja a Sextiliano, gran aficionado a la bebida, el cual llega a las tabernas de Roma en grandes cantidades, y de la «Laeetana copia nobilitantur» de 
Plinio (H.N. 14.71), famoso pues por su cantidad. Sin embargo, a los otros tres caldos de la Tarraconense (de Tarraco, Lauro y Baleares) los compara con los mejores de Italia. Así pues, a Roma llegaba vino layetano abundante muy probablemente en dolia y otro de diferentes calidades en ánforas Dressel 3-2.

En resumen, distinto envase, distinta calidad de vino, distinto destino. Arqueología y fuentes escritas parecen coincidir, afortunadamente.

\section{CONCLUSIONES}

Ya desde el inicio de su fundación, Barcino estuvo dotada de una infraestructura encaminada a la función de control y administración del territorio layetano, así como de centro impulsor y distribuidor de productos agrícolas de la Layetania occidental y de punto de llegada de mercancías foráneas. Si bien durante la República tardía la parte oriental había sido capitalizada por Baetulo e Iluro, esto es, los centros litorales más romanizados y desarrollados económicamente, es ahora cuando toman el relevo las comarcas del Barcelonès, Baix Llobregat y Vallès occidental, que como hemos visto, forman el núcleo de la Layetania occidental y a lo que sin duda alguna contribuyó su privilegiada situación geográfica.

Su fundación contribuyó a la descentralización de la producción de excedentes vinícolas de la Layetania oriental desde la segunda mitad del siglo I a.C. y a su reconversión enfocada a la exportación vía marítima, proceso iniciado a principios de la segunda mitad del $\mathrm{s}$. I a.C. En estos años tardorrepublicanos ya observamos la existencia de centros de producción y almacenaje de vino en su territorio en forma de villae suburbanas, cuya continuidad se mantiene y aumenta su importancia con la fundación de la ciudad.

Paralelamente, se construyen en el suburbium y ager de Barcino una serie de alfares dedicados a la fabricación de ánforas Pascual 1 y Dressel 3-2, para la exportación de estos excedentes vinícolas. Se trata de los continuadores de las Tarraconense 1 de décadas anteriores, en realidad los primeros balbuceos en la exportación de vinos layetanos, antes de la existencia de Barcino. Cronológicamente, estas exportaciones de vino de consumo abundante en Pascual 1 se inician hacia 40-30 a.C., focalizadas por Baetulo e Iluro. En la última década de la centuria, Barcino tomaría el relevo, dotada desde el principio con una sencilla infraestructura portuaria para cargar las naves frente a la puerta decumana. De hecho, será la continuación de la ya existente en Montjuic y por otra parte, de la de Les Sorres, la otra salida natural de los barcos desde época tardorrepublicana, y su destino principal serán prioritariamente las élites galas vía Narbo, auténtico centro receptor y redistribuidor de estas mercancías.

Con el cambio de era, la Dressel 3-2 va ocupando progresivamente el lugar de la Pascual 1, dirigiéndose las naves, a veces también con vino almacenado en $d o-$ lia, principalmente a Ostia/Roma y quizás en segundo lugar, a Cartago. La calidad del vino se diversifica, produciendo la zona de Lauro, centralizada en Aquae Calidae, el vino lauronense. Poco después de mediados del s. I d.C. estas exportaciones disminuyen, para desaparecer progresivamente, mientras que la producción del vino de Tarraco va ocupando su lugar en la producción y posiblemente exportación del vino tarraconense.

Los sellos en estas ánforas nos informan de los protagonistas, tanto de los propietarios de las figlinae fabricantes de las ánforas y de los fundi donde se producía el vino, como de los agentes involucrados en la producción anfórica y en su comercio. Contamos, además, con la aportación de la toponimia altomedieval, heredera de la romana, con el nombre de las propiedades derivado del de sus propietarios, para localizar estos terrenos en la Layetania. Todo ello unido a la epigrafía monumental y honorífica de la colonia, nos proporciona sólidos indicios para deducir que las gentes más renombradas en la ciudad se beneficiaron ampliamente de este lucrativo y especulativo comercio ya desde el principio, como propietarios fundiarios y del vino, sin duda el producto más valioso de sus tierras. De este negocio se lucraron igualmente sus libertos (y no solo los de estas familias, sino tal vez los imperiales), piezas fundamentales en el proceso de la producción anfórica y de la infraestructura necesaria para llevar a cabo el transporte de los envases desde los talleres a los puertos para su embarque. La riqueza y prosperidad de las élites que vivían en Barcino, así como el desarrollo económico y comercial de la ciudad desde su fundación, pueden explicarse en gran parte gracias a este fenómeno, que marcó el devenir de la ciudad romana, tan unida al mar desde entonces y para siempre.

\section{Agradecimientos}

A Piero Berni Millet (UMR5140 ASM-Montpellier/LabEx; Institut Català d'Arqueologia Clàssica, Tarragona, Investigador adscrito). Él es en gran parte el coautor entre líneas y en ellas de este estudio. A César Carreras y Oriol Olesti (Universitat Autònoma de Barcelona), por las facilidades para la reproducción de sus figuras. 
Esta investigación ha sido realizada dentro del proyecto Amphorae Ex Hispania: Sistematización y Accesibilidad en red de los centros de producción (I+D HAR2015-68554-P) . “

\section{BIBLIOGRAFIA}

Abascal Palazón, J.M. (1994): Los nombres personales en las inscripciones latinas de Hispania. Murcia, Universidad Complutense de Madrid y Universidad de Murcia.

Aguelo i Mas, J.; Carreras Monfort, C. y Huertas Arroyo, J. (2006): "L'ocupació altimperial del solar del mercat de Santa Caterina. Un posible centre productor ceràmic". QUARHIS: Quaderns d'Arqueologia $i$ Història de la Ciutat de Barcelona 2: 60-73.

Aguelo Mas, J. y Huertas Arroyo, J. (2009): “Una terrisseria epigráfica: El solar del mercat de Santa Caterina de Barcelona en el moment altimperial romà", en Barcino I. Marques i terrisseries d'àmfores al Pla de Barcelona. Union Académique Internationale. Corpus International des Timbres Amphoriques 15: 89-95. Barcelona, Institut d'Estudis Catalans - Institut Català d'Arqueologia Clàssica.

Alcubierre, D.; Hinojo, E. y Rigo, A. (2014): "Primers resultats de la intervenció a la vil.la romana del Pont del Treball a Barcelona". Tribuna d'Arqueologia 2011-2012: 372-389.

Antequera, F., Padrós, P., Rigo, A. y Vázquez, D. (2010): "El suburbium occidental de Baetulo", , en D. Vaquerizo (ed.), Las áreas suburbanas en la Ciudad Histórica. Topografía, usos, función. Monografías de arqueología cordobesa 18: 173-210. Córdoba, Ayuntamiento de Córdoba-Universidad de Córdoba

Armani, S. (2014): "Les C. Iulii et la posterité des noms d'Auguste en Citérieure: étude d'onomastique provinciale". Veleia 31: 79-98.

Arnaud, P. (2005): Les routes de la navigation antique. Itinéraires en Méditérranée. Paris, Editions Errance.

Asensio i Vilaró, D.; Cela Espín, X.; Miró i Alaix, C.; Miró i Alaix, M.T. y Revilla i Cubero, E. (2009): "El nucli ibèric de Montjuïc. Les sitges de Magòria o de Port. Barcelona". QUARHIS: Quaderns d'Arqueologia $i$ Història de la Ciutat de Barcelona 5: 15-85.

Barreda, A. (1998): "La gens Mussidia en las ánforas Pascual 1", en El vi a l'antiguitat. Economia, producció $i$ comerç al Mediterrani occidental. Actes del II Col.loqui Internacional d'arqueologia romana: 332-340. Monografies Badalonines 14. Badalona (1998) Badalona, Museu de Badalona.

Beltrán de Heredia, J. (2010): "La cristianización del suburbium de Barcino", en D. Vaquerizo (ed.), Las áreas suburbanas en la Ciudad Histórica. Topografia, usos, función. Monografías de arqueología cordobesa 18: 363-396. Córdoba, Ayuntamiento de Córdoba-Universidad de Córdoba.

Berges, M. (1970: "Los hallazgos arqueológicos submarinos ingresados en el Museo Arqueológico de Tarragona. Boletín Arqueológico de Tarragona 6970: 3-15.

Bernard, H. (1996): "Marina di Fiori”. Bilan Scientifique du Département des Recherches Archéologiques Subaquatiques et Sous-marines: 113. Marseille, Ministère de la Culture et de la Communication.

Berni Millet, P. (2010): "Epigrafia sobre amphorae, tegulae, imbrex i dolia a l'àrea occidental del Camp de Tarragona", en Ager Tarraconensis 3. Les inscripcions romanes: 153-210. Tarragona, Institut Català d'Arqueologia Clàssica.

Berni Millet, P. (2015a): "Novedades sobre la tipología de las ánforas Dressel 2-4 tarraconenses". Archivo Español de Arqueología 88:187-201. http:// doi.org/10.3989/aespa.088.015.010.

Berni Millet, P. (2015b): "Novedades de epigrafía anfórica en el Baix Llobregat", en V. Martínez Ferreras (ed.), La difusión comercial de las ánforas vinarias de Hispania Citerior Tarraconensis (s. I a.C. - I d.C.). Archaeopress Roman Archaeology 4: 5566. Oxford, Archaeopress.

Berni Millet, P. (2017): “Dynamiques économiques de la production et du commerce des amphores Dressel 3-2 léetaniennnes". Revue Archéologique de Narbonnaise 50: 215-228.

Berni Millet, P.; Carreras Monfort, C. y Revilla Calvo, V. (1998): "Sobre dos nuevos Cornelii del vino tarraconense". Laietània 11: 111-123.

Berni Millet, P. y Carreras Monfort, C. (2001): "El circuit comercial de Barcino: reflexions al voltant de les marques amfòriques". Faventia 32 (1): 103-129.

Berni, P.; Carreras Monfort, C. y Olesti, O. (2005): "La gens Licinia y el Nordeste peninsular. Una aproximación al estudio de las formas de propiedad y de gestión de un rico patrimonio familiar". Archivo Español de Arqueología 78: 167-187.

Berni Millet, P. y Carreras Monfort, C. (2013): “Corpus epigràfic de segells en àmfores, dolia, tegulae i gerres de ceràmica comuna oxidada del Baix Llobregat", en Barcino II. Marques i terrisseries d'àmfores 
al Baix Llobregat. Union Académique Internationale. Corpus International des Timbres Amphoriques 18: 127-285. Barcelona, Institut d'Estudis Catalans - Institut Català d'Arqueologia Clàssica.

Berni Millet, P. y Miró Canals, J. (2013): “Dinámica socioeconómica en la Tarraconense Oriental a finales de la República y comienzos del Imperio”, en J. López Villar (ed.), Tarraco Bienal. Actes. Govern i societat a la Hispana romana. Novetats epigràfiques. Homenatge a Géza Alföldy: 63-83. Tarragona (2012), Tarragona, Fundació Privada Mútua Catalana.

Berni Millet, P. y Miró Canals, J. (en prensa): "Vino layetano y de Tarraco en Cartago. Contribución de la epigrafía anfórica al conocimiento del desarrollo económico de la Layetania en época julio-claudia”. Antiquités Africaines 56.

Carreras Monfort, C. (2009a): "Preliminars. L'estudi del territori de la colònia i les primeres terrisseries" en Barcino I. Marques i terrisseries d'àmfores al Pla de Barcelona. Union Académique Internationale. Corpus International des Timbres Amphoriques 15: 11-20. Barcelona, Institut d'Estudis Catalans - Institut Català d'Arqueologia Clàssica.

Carreras Monfort, C. (2009b): "Les marques d'àmfores produides als tallers de Barcino", en Barcino I. Marques $i$ terrisseries d'àmfores al Pla de Barcelona. Union Académique Internationale. Corpus International des Timbres Amphoriques 15: 21-44. Barcelona, Institut d'Estudis Catalans - Institut Català d'Arqueologia Clàssica.

Carreras Monfort, C. (2013): "Evolució de les terrisseries del Baix Llobregat a partir de les seves marques i els seus derelictes", en Barcino II. Marques $i$ terrisseries d'àmfores al Baix Llobregat. Union Académique Internationale. Corpus International des Timbres Amphoriques 18: 323-346. Barcelona, Institut d'Estudis Catalans - Institut Català d'Arqueologia Clàssica.

Carreras Monfort, C. (2015): "Novedades en torno a la producción y distribución de las ánforas del Ager Barcinonensis (El Baix Llobregat)", en V. Martínez Ferreras (ed.), La difusión comercial de las ánforas vinarias de Hispania Citerior Tarraconensis (s. I a.C. - I d.C.). Archaeopress Roman Archaeology 4: 67-78. Oxford, Archaeopress.

Casas Blasi, J. (2009): "Una terrisseria del pla de Barcelona: l'excavació del carrer de la Princesa, $n^{\circ} 21$ ", en Barcino I. Marques i terrisseries d'àmfores al Pla de Barcelona. Union Académique Internationale. Corpus International des Timbres Amphoriques 15:
63-88. Barcelona, Institut d'Estudis Catalans - Institut Català d'Arqueologia Clàssica.

Christol, M. y Plana Mallart, R. (1997): "Els negotiatores de Narbona i el vi català". Faventia 19 (2): 75-95.

Colls, D. (1986): “Amphores léetaniennes de l'épave Cap Béar III”. Revue des Études Anciennes 88: 201213. https://doi.org/10.3406/rea.1986.4238.

Colls, D.; Castellvi, G.; Salvat, M; Martínez-Ferreras, V. y Jézégou, M.P. (2015): "L'épave Port-Vendres 4. Un exemple de commerce d'exportation à partir d'un port de Tarraconaise (Ier s. av. J.C.)", en V. Martínez Ferreras (ed.), La difusión comercial de las ánforas vinarias de Hispania Citerior Tarraconensis (s. I a.C. - I d.C.).

Comas i Solà, M. (1985): Baetulo. Les àmfores. Monografies Badalonines 8. Badalona, Museu de Badalona.

Comas i Solà, M. (1997): Baetulo. Les marques d'àmfora, Union Académique Internationale. Corpus International des Timbres Amphoriques 2. Barcelona, Institut d'Estudis Catalans - Museu de Badalona.

Corsi-Sciallano, M. y Liou, B. (1985): "Les épaves de Tarraconaise à chargement d'amphores Dressel 2-4". Archaeonautica 5. Paris, Éditions du CNRS.

Dell'Amico, P. y Pallarés, F. (2007): "Le anfore della Laietania. Appunti e riflessioni". Archaeologia Maritima Mediterranea. An International Journal on Underwater Archaeolog 4: 53-133.

Dell'Amico, P. y Pallarés, F. (2011): “Appunti sui relitti a dolia”. Archaeologia Maritima Mediterranea 8: 47-135.

Étienne, R. y Mayet, F. (2000): Le vin hispanique. Paris, Diffusion E. de Boccard.

Gianfrotta, P.A. (1982): "Lentulo Augure e le anfore laietane". Tituli 4: 475-479.

Gianfrotta, P.A. y Hesnard, A. (1987): "Due relitti augustei carichi di dolia: quello di Ladispoli e del Grand Ribaud D", en El vi a l'antiguitat. Economia, producció i comerç al Mediterrani Occidental. Actes: 285-297. Badalona (1985), Badalona, Museu de Badalona.

González Cesteros, H. (2015): “Hallazgos de productos tarraconenses en la frontera germana, Un mercado secundario", en V. Martínez Ferreras (ed.), La difusión comercial de las ánforas vinarias de Hispania Citerior Tarraconensis (s. I a.C. - I d.C.). Archaeopress Roman Archaeology 4: 205-220. Oxford, Archaeopress.

González Cesteros, H y Berni Millet, P. (2018): Roman Amphorae in Neuss. Augustan to Julio-claudian 
contexts. Roman and Late Antique Mediterranean Pottery 12. Oxford, Archaeopress.

Gorostidi Pi, D. (2013): "Sobre les marques Syn/Syne i la seva identificació amb C. Trocina Synecdemus, sevir augustal de la colònia de Barcino", en Barcino II. Marques i terrisseries d'àmfores al Baix Llobregat. Union Académique Internationale. Corpus International des Timbres Amphoriques 18: 287-296. Barcelona, Institut d'Estudis Catalans - Institut Català d'Arqueologia Clàssica.

Granados, O. (1991): "Estructura urbana de la ciudad romana", en J. Sobrequés (dir.), Història de Barcelona I. La ciutat antiga: 141-201. Barcelona, Enciclopèdia Catalana - Ajuntament de Barcelona.

Guitart Durán, J. (1976): Baetulo. Topografía arqueológica, urbanismo e historia. Monografías Badalonesas 1. Barcelona, Museo Municipal de Badalona - Excmo. Ayuntamiento de Badalona.

Guitart i Duran, J. (1987): "La Laietània: el context històrico-arqueològic com a marc interpretatiu de la producció i começ del vi a la regió", en $E l$ vi a l'antiguitat. Economia, producció $i$ comerç al Mediterrani Occidental. Actes: 145-151. Badalona (1985), Badalona, Museu de Badalona.

Hernández-Gasch, J. (2006): The Castellum of Barcino: from its Early Roman Empire origins as a monumental place to the Late Antiquity fortress". QUARHIS: Quaderns d'Arqueologia i Història de la Ciutat de Barcelona 2: 75-91.

Hesnard, A. (1980). "Un dépôt augustéen d'amphores à La Longarina, Ostie”, en J.H. d'Arms y E.C. Kopff (ed.), The Seaborne Commerce of Ancient Rome: Studies in Archaeology and History. Memoirs of the Amercian Academy in Rome, 36: 141-156.

IRC IV = Fabre, G; Mayer, M. y Rodà, I. (1997): Inscriptions Romaines de Catalogne. IV. Barcino. Paris, Diffusion de Boccard.

Izquierdo i Tugas, P. (2000): “Intervenció arqueològica al Pont del Diable (Martorell/Baix Llobregat-Castellbisbal/Vallès Occidental). Resultats de la primera fase", en Tribuna d'Arqueologia 1997-1998: 39-53. Barcelona, Departament de Cultura de la Generalitat de Catalunya.

Izquierdo i Tugas, P. (2009): "Els ports del litoral tarraconense i el seu paper en el comerç del vi”, en El vi tarraconense i laietà: ahir $i$ avui. Actes del simposium. Documenta 7: 179-191. Tarragona y Teià (2007), Tarragona, Institut Català d'Arqueologia Clàssica.

Izquierdo i Tugas, P. (2013): "L'ancoratge de Les Sorres: el port de la vall del Llobregat", en Barcino II. Marques i terrisseries d'àmfores al Baix Llobregat.
Union Académique Internationale. Corpus International des Timbres Amphoriques 18: 309-322. Barcelona, Institut d'Estudis Catalans - Institut Català d'Arqueologia Clàssica.

Járrega Domínguez, R. (2011): “El port romà de Barcino (Barcelona) i el Praefectus Orae Maritimae Laeetanae. Un posible portus comercial". Butlletí Arqueologic Tarragona V, 33: 81-119.

Járrega Domínguez, R. (2013): "Producción anfórica, figlinae y propiedad en el territorium de Tarraco (Hispania Citerior): últimas aportaciones", en D. Bernal, L.C. Juan, M. Bustamente, J.J. Díaz y A.M. Sáez (eds.): Hornos, talleres y focos de producción alfarera en Hispania. Monografías Ex Officina Hispana I: 399-410. Cádiz (2011), Cádiz, Servicio de Publicaciones de la Universidad de Cádiz.

Járrega Domínguez, R. (2016a): "Personajes foráneos en la epigrafía de las ánforas Pascual 1 y Oberaden 74. Aproximación a los cambios en la gestión de la producción vinaria en la Hispania Citerior en época de Augusto". Dialogues d'Histoire Ancienne 42 (2): 155-190. http://doi.org/10.3917/dha.422.0155.

Járrega Domínguez, R. (2016b): "Los nomina en las marcas de ánforas de las formas Pascual 1 y Oberaden 74. Contribución al estudio de la producción de ánforas vinarias en el noreste de la Hispania Citerior en época de Augusto". Revista d'Arqueologia de Ponent 26: 73-93. http://doi.org/10.21001/ rap.2016.26.3.

Járrega Domínguez, R. (2018): “Los nomina en la epigrafía anfórica de las ánforas Dressel 2-4 del NE de la Hispania Citerior. Cambios estructurales e implicación de las élites urbanas". Saguntum 50: 175202. http//doi.org/10.7203/SAGVNTVM.

Járrega R. y Otiña, P. (2008): “Un tipo de ánfora tarraconense de época medioimperial (siglos II-III): la Dressel 2-4 evolucionada", en SFECAG. Actes du Congrès de l'Escala-Empúries: 281-286. L'Escala - Empúries (2008), Marseille, Société Française d' Etude de la Céramique Antique.

Laubenheimer, F. (2015): "Les circuits d'exportation des vins de Tarraconaise en Gaule" en V. Martínez Ferreras (ed.), La difusión comercial de las ánforas vinarias de Hispania Citerior Tarraconensis (s. I a.C. - I d.C.). Archaeopress Roman Archaeology 4: 181-192. Oxford, Archaeopress.

Liou, B. (1987): “L'exportation de vin de Tarraconaise d'après les épaves", en El vi a l'antiguitat. Economia, producció i comerç al Mediterrani Occidental. Actes: 271-284. Badalona (1985), Badalona, Museu de Badalona. 
Liou, B. y Pomey, P. (1985): "Informations archéologiques". Gallia 43: 547-551.

López Mullor, A. y Martín Menéndez, A. (2008). "Las ánforas de la Tarraconense", en J. Bernal y A. Ribera (eds.), Cerámicas hispanorromanas. Un estado de la cuestión: 689-724. Cádiz, Servicio de Publicaciones de la Universidad de Cádiz.

Mar, R.; Garrido, A y Beltrán-Caballero, J.A. (2012): "Barcino y el urbanismo provincial romano", en R. Grau (coord.), Presència i lligams territorials de Barcelona. vint segles de vida urbana. Barcelona Quaderns d'Història 18: 63-112. Barcelona, Ajuntament de Barcelona, Institut de Cultura.

Marlier, S. (2008): "Architecture et espace de navigation des navires à dolia". Archaeonautica 15: 155 175. https://doi.org/10.3406/nauti.2008.920.

Martín Menéndez, A. (2008): “Àmfores tarraconenses i bètiques en els derelictes de mitjan segle I a.C. a la costa catalana", en SFECAG, Actes du Congrès de L'Escala-Empúries: 103-127. L'Escala - Empúries (2008), Marseille, Société Française d'Etude de la Céramique Antique.

Martín i Menéndez, A. y García Roselló, J. (2007): “La vall de Cabrera de Mar. focus inicial de la producció vitivinícola a la Laietània", en Pottery workshops and agricultural productions. Studies of the rural world in the roman period, (vol. 2): 69-82. Girona, Universitat de Girona, Servei de Publicacions.

Martín i Oliveras, A.; Rodà de Llanza, I. y Velasco i Felipe C. (2007): "Cella vinaria de Vallmorà (Teià, Barcelona). Un modelo de explotación vitivinícola intensiva en la Layetania, Hispania Citerior (s. I a.C. - s. V d.C.)". Histria Antiqua 15: 195-212.

Martínez Ferreras, V. (2012): “El estudio arqueométrico de las ánforas vinícolas. Una nueva forma de aproximarnos al conocimiento de la producción y exportación del vino de la Tarraconensis", en J.M. Noguera Celdrán y J.A. Antolinos Marín (eds.), De vino et oleo Hispaniae. Áreas de producción y procesos tecnológicos del vino y el aceite en la Hispania romana. Coloquio internacional. Anales de Prehistoria y Arqueología, 27-28: 513-525. Murcia (2010), Murcia, Universidad de Murcia.

Martínez Ferreras, V. (2014): Anforas vinarias de Hispania Citerior-Tarraconensis (s. I a.C.-I d.C.). Caracterización arqueométrica. Roman and Late Mediterranean Pottery 4. Oxford, Archaeopress.

Martínez Ferreras, V. (ed.) (2015): La difusión comercial de las ánforas vinarias de Hispania Citerior Tarraconenses (s. I a.C. - I d.C.). Archaeopress Roman Archaeology 4. Oxford, Archaeopress.
Martínez Ferreras, V.; Buxeda i Garrigós, J.; Gurt i Esparraguera, J.M. y Kilikoglou, V. (2007): “Archaeometric characterisation of Roman wine amphorae from Barcelona (Spain)", en S.Y. Waksman (ed.), Archaeometric and Archaeological Approaches to Ceramics: 113-119. BAR Internacional Series 1691. Oxford, Archaeopress.

Martínez Ferreras, V.; Capelli, C.; Cabella, R. y Nieto Prieto, X. (2013): "From Hispania Tarraconensis (NE Spain) to Gallia Narbonensis (S France). New data on Pascual 1 amphora trade in the Augustan period". Applied Clay Science 82: 70-78. http://doi. org/10.1016/j.clay.2013.06.021.

Martínez Ferreras, V.; Jézégou, M.P.; Descamps, C. y Salvat, M. (2014). "La proveniencia de las ánforas vinarias tarraconenses del pecio Port-Vendres 5 (Pirineos Orientales, Francia), en X. Nieto y M. Bethencourt (ed.), Arqueología subacuática española. Actas del I Congreso de Arqueología Náutica y Subacuática Española I: 95-106. Cartagena (2015), Editorial UCA.

Martínez Ferreras, V.; Capelli, C.; Jézégou, M.P.; Salvat, M.; Castellvi, G. y Cabella, R. (2015): "The PortVendres 4 Shipwreck Cargo: evidence of the Roman wine trade in the Western Mediterranean". The International Journal of Nautical Archaeology: 1-23.

Mauné, S. (2012): "Un timbre de Q. Iulius Teophilus sur Pascual 1 à Aspiran (Hérault). Un nouvel indice des liens économiques entre les provinces de Tarraconaise et de Narbonnaise au début du Ier s. ap. J.-C.?". RAN 45:143-161. https://doi.org/10.3406/ ran.2012.1834.

Mayer i Olivé, M. (1996): Gal.la Placídia i la Barcelona del segle $V$. Barcelona, Reial Acadèmia de Bones Lletres de Barcelona.

Miró, J. (1988): La producción de ánforas romanas en Catalunya. Un estudio sobre el comercio del vino de la Tarraconense (siglos I a.C.-I d.C.). BAR Internacional Series 473. Oxford, B.A.R.

Miró Canals, J. y Járrega Domínguez, R. (2018): “Les ateliers de production d'amphores ovoïdes du NordEst d'Hispania Citerior (Tarraconensis) aux époques tardo-républicaine et augustéenne précoce. Revue Archéologique de Narbonnaise 50-51: 209-221.

Miró Canals, J. y Járrega Domínguez, R. (2019): “Anforas ovoides del noreste de la Hispania Citerior Tarraconensis en época tardorepublicana. Ensayo de síntesis", en E. García Vargas, R. Roberto de Alemida, H. Gonzáelz Cesteros y A. M. Sáez Romero (eds.), The Ovoid Amphorae in the Central 
and Western Mediterranean. Mediterranean Pottery 13: 148-174. Oxford, Archaeopress.

Morera J.; Olesti, O. y Carreras, C. (2010): “Centres de producció amfòrica i territori a la riba dreta del Llobregat: novetats de la terrisseria del Mercat (Sant Vicenç dels Horts)". Pyrenae 41(2): 49-79.

Moret Pujol, L.; Carreras Monfort, C. y Miró i Alaix, C. (2013): "Terrisseries al voltant de la riera de Rubí: Can Tintorer (El Papiol) i Can Pedrerol de Baix (Castellbisbal)", en Barcino II. Marques $i$ terrisseries d'àmfores al Baix Llobregat. Union Académique Internationale. Corpus International des Timbres Amphoriques 18: 17-32. Barcelona, Institut d'Estudis Catalans - Institut Català d'Arqueologia Clàssica.

Nieto, X. y Raurich, X. (1998): "El transport naval del vi de la Tarraconense", en El vi a l'antiguitat. Economia, producció i comerç al Mediterrani occidental. Actes del II Col.loqui Internacional d'arqueologia romana: 113-137. Monografies Badalonines 14. Badalona (1998) Badalona, Museu de Badalona.

Olcese, G.; Cau Ontiveros, M.A.; Fantuzzi, L.; Razza, A.; Surace, D.M. y Tsantini, E. (2017): "Le anfore del contesto della ruota hidráulica di Ostia antica: archeologia e archeometria". Archeologia Classica 68 (2) 7: 197-224. https://doi.org/10.1400/258248.

Olesti Vila, O. (2005): "Propiedad de la tierra y élites locales. El ejemplo del ager barcinonenis", en Histoire, espaces et marges dans l'Antiquité. Hommages à Monique Clavel-Lévêque (vol. 4): 175-200. Besançon, Institut des Sciences et Techniques de l'Antiquité.

Olesti Vila, O. (2009): "Propietat i riquesa a l'ager Barcinonensis", en Barcino I. Marques i terrisseries d'àmfores al Pla de Barcelona. Union Académique Internationale. Corpus International des Timbres Amphoriques 15: 141-158. Barcelona, Institut d'Estudis Catalans - Institut Català d'Arqueologia Clàssica.

Olesti Vila, O. y Carreras Monfort, C. (2013): "Le paysage social de la production vitivinicole dans l'ager Barcinonensis: esclaves, affranchis et institores». Dialogues d'Histoire Ancienne 39(2): 147190. http://doi.org/10.3917/dha.392.0147”.

Olesti Vila, O. y Carreras Monfort, C. (2015): "De servus a propietario agrícola: el esclavo en el mundo de la producción anfórica en el Ager Barcinonensis", en Los espacios de la esclavitud y la dependencia en la Antigüedad. Homenaje a Domingo Plácido. Actas del XXXV Coloquio del GIREA: 561-587. Madrid (2012), Madrid, Centro de Ciencias Humanas y Sociales del CSIC.
Ortiz de Urbina Álava, E. (2014): "Los C. Ivlii y la posteridad de los nombres de Augusto en Hispania $\mathrm{C} i$ terior: estudio de su proyección civil y militar". Veleia 31: 99-121.

Padrós Martí, P.; Antequera Devesa, F.; Granollers Mesa, M.; Rigo Jovells, A. y Vázquez Álvarez, D. (2013): "El complejo alfarero de Illa Fradera y el papel de Baetulo en el comercio del vino layetano, siglos I a.C./I d.C.”, en D. Bernal, L.C. Juan, M. Bustamente, J.J. Díaz y A.M. Sáez (eds.): Hornos, talleres y focos de producción alfarera en Hispania. Monografías Ex Officina Hispana I: 439-454. Cádiz (2011), Cádiz, Servicio de Publicaciones de la Universidad de Cádiz.

Palet i Martínez, J.M. (1997): Estudi territorial del Pla de Barcelona. Estudis i Memòries d'Arqueologia de Barcelona. Barcelona, Ajuntament de Barcelona - Institut de Cultura.

Parker, A.J. (1992): Ancient Shipwrecks of the Mediterranean \& the Roman Provinces. BAR International Series 580. Oxford, BAR.

Pascual, R. (1962): “Centros de producción y difusión geográfica de un nuevo tipo de ánfora”, en VII Congreso Nacional de Arqueología: 334-345. Barcelona (1960), Zaragoza, Secretaría General de los Congresos Arqueológicos Nacionales.

Pascual Guasch, R. (1977): "Las ánforas de la Layetania”, en Méthodes classiques et méthodes formelles dans l'étude des amphores. Actes du colloque de Rome: 4796. Roma (1974), Roma, Ecole Française de Rome.

Pascual i Guasch, R. (1991): Index d'estampilles sobre àmfores catalanes. Cuadernos de Arqueología, 5. Barcelona, Edicions Servei del Llibre L'Estaquirot.

Peña Cervantes, Y. (2010): Torcularia. La producción de vino y aceite en Hispania. Serie Documenta 14. Tarragona, ICAC.

Peña Cervantes, Y. y Miró i Alaix, C. (2017): "Explotació de la Carta Arqueológica de Barcelona: la viticultura a la colònia Barcino", en Anuari d'Arqueologia i patrimoni de Barcelona 2015: 1117. Barcelona, Ajuntament de Barcelona.

Pons Sala, J. (1977): “Algunas consideraciones teóricas sobre el sevirato como indicador de dinamismo socio-económico". Memorias de Historia Antigua 1: 215-219.

Pons i Sala, J. (1985): "Propietats agràries d'Itàlics a Catalunya. Consideracions a l'entorn de les mansions de la Vía Augusta que duen el sufix -ana-“. Pyrenae 21: 129-139.

Revilla Calvo, V. (2007): “Onomástica en epigrafía anfórica de la Hispania Tarraconense: algunas 
consideraciones sobre significado y métodos de análisis", en Acta XII Congressus Internationalis Epigraphiae Graecae et Latinae: 1183-1192. Barcelona (2002), Barcelona, Institut d'Estudis Catalans.

Riba i Arderiu, A. O. y Colombo i Piñol, F. (2009): Barcelona: la Ciutat Vella i el Poble Nou. Assaig de geologia urbana. Barcelona, Institut d'Estudis Catalans - Reial Acadèmia de Ciències i Arts de Barcelona.

RIT= Alfoldy, G. (1975): Die Romischen Inschriften von Tarraco. Madrider Forschungen, 10. W. de Gruyter, Berlin.

Rizzo, G. (2014): “Ostia VI. Le terme del Nuotatore. Le anfore, Ostia e in commerci mediterranei. Studi Miscellanei 38: 197-398.

Rizzo, G. (2018): “Ostia, le anfore ei commerci mediterranei. Un bilancio preliminare”. Archeologia Classica 69 (2): 223-266. http://doi.org/10.4000/ mefra.2042.

Rodà de Llanza, I. (1970): “Lucius Licinius Secundus, liberto de Lucius Licinius Sura”. Pyrenae 6: 167-183.

Rodà de Llanza, I. (2010): "La promoción de las élites en las ciudades del Conventus Tarraconensis", en F.J. Navarro (ed.), Pluralidad e integración en el mundo romano. Col. Mundo Antiguo 13: 177-188. Pamplona, Ediciones Universidad de Navarra.

Rodà, I. (1991): "Les activitats econòmiques", en J. Sobrequés (dir.), Història de Barcelona I. La ciutat antiga: 385-418. Barcelona, Enciclopèdia Catalana - Ajuntament de Barcelona.

Rodà, I. (2014): "Lucius Licinius Sura, Hispanus", en Trajan und seine städte. Colloquium Cluj-Napoca: 21-35. Cluj-Napoca (2013), Editura Mega.

Rodà de Llanza, I.; Martín i Oliveras, A.; Velasco i Felipe, C. y Arcos i López, R. (2005): "Personatges de Barcino i el vi laietà". QUARHIS: Quaderns d'Arqueologia i Història de la Ciutat de Barcelona 1: 47-57.

Sánchez, C. (2015): "Les amphores de Tarraconaise dans les contextes narbonnais", en V. Martínez Ferreras (ed.) (2015): La difusión comercial de las ánforas vinarias de Hispania Citerior Tarraconenses (s. I a.C. - I d.C.): 165-180. Archaeopress Roman Archaeology 4. Oxford, Archaeopress.
Sciallano, M. y Marlier, S. (2008): "L'épave à dolia de l'île de la Giraglia (Haute-Corse)". Archaeonautica 15: 113-151. http://doi.org/10.3406/nauti.2008.919.

Tarradell Mateu, M. (1975): "Barcelona antiga", en A. Durán i Sanpere (dir.), Història de Barcelona: 56146. Barcelona, Ed. Aedos.

Tarradell, M. (1978): "La romanització", en J. Salvat (dir.), Història de Catalunya I: 216-238. Barcelona. Salvat Ed.

Tchernia, A. (1971): "Les amphores vinaires de Tarraconaise et leur exportation au début de l'Empire". Archivo Español de Arqueología 44: 38-85.

Tchernia, A. (1986): Le vin de l'Italie romaine. Essai d'historie économique d'après les amphores. Roma, Ecole Française de Rome.

Tchernia, A. (1987): "Modèles économiques du vin à la fin de la République et au début de l'Empire", en $E l$ vi a l'antiguitat. Economia, producció i comerç al Mediterrani Occidental. Actes: 327-346. Badalona (1985), Badalona, Museu de Badalona.

Terrado Ortuño P. (2019): El puerto de Tarraco en época romana (siglos II a.C. - III d.C.). Fuentes, historiografía y arqueología. Tarragona, Autoritat Portuaria de Tarragona - Arola Editors.

Tremoleda i Trilla, J. (1998): "Publius Usulenus Veiento, un magistrat narbonès amb propietats al nord de la Tarraconense", en Comerç $i$ vies de comunicació (1000 aC-700 dC). XI Col.loqui Internacional d'Arqueologia de Puigcerdà: 231-241. Puigcerdá (1997), Patronat Francesc Eiximenis, Ajuntament de Puigcerdà y Govern d'Andorra.

Tremoleda Trilla, J. (2005): "Un nou inversor itàlic en la viticultura de la Tarraconense: Publi Baebi Tuticà". Pyrenae 36(2): 115-140.

Vila, O. O. y Monfort, C. C. (2008): “Tierra y libertad: libertos y institores en el ager barcinonensis (Barcelona)", en Arqueología e historia del Mundo antiguo: contribuciones brasileñas y españolas. BAR International Series 1791: 93-103. Oxford, BAR.

Vivar, G., de Juan, C. y Geli, R. (2015): “Cap del Vol. Un producte, un vaixell $\mathrm{i}$ un comerç del Conventus Tarraconensis en época d'August', en Tribuna d'Arqueologia 2012-2013: 11-21. Barcelona, Departament de Cultura de la Generalitat de Catalunya. 